تحالف العمل الإشراِِّ والفاعلية الذاتية الإرشادية للمتدريين: تضمينات لتطوير برامج تدريب طلبة الإرشاد

\author{
جهاد محمود علاء الدين \\ الجامعة الهاشمية، الزرقاء، الأردن
}

قُبل بتاريخ: م⿸广/

عُل عُ بتاريخ:

استتلم بتاريخ:

تهدف الدراسة الحالية استتاداً إلى نموذج بوردين (r/91) لاستكشاف ما إذا كانت إدراكات المشرفين والمرشدين المتدربين لتحالف العمل

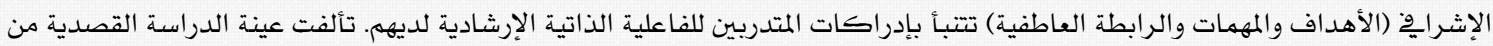

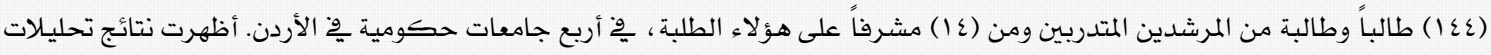

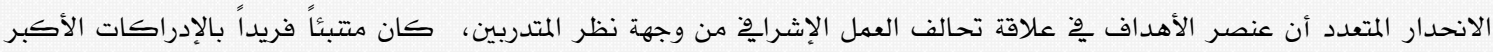

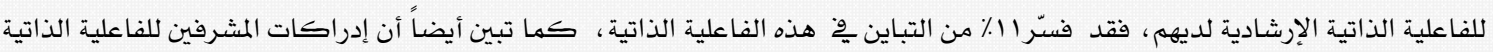

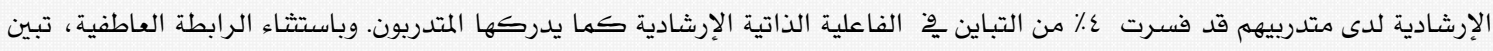

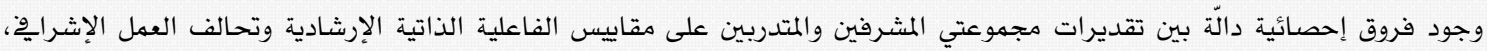
لصالح المتدربين الذين سجلوا درجات أعلى. تضم الدراسة تضمينات لعملية الإشراف ومقترحات لتحسينها ولدراسات مستقبلية. كلمات مفتاحية: نموذج بوردين لتحالف العمل الإشراوّ؛؛ الفاعلية الذاتية الإرشادية؛ مشرفون وطلبة مرشدون متدربون.

\title{
Supervisory Working Alliance and Trainees' Counseling Self-Efficacy: I mplications for Developing Training Program of Counseling Students
}

\author{
Jehad M. Alaedein* \\ Hashemite University, Zarqa, Jordan
}

The study, based on the model of Bordin (1983), aims to explore whether the supervisors' and trainees' perceptions of supervisory working alliance (goals, tasks and emotional bond) predict trainees' perceptions of counseling self-efficacy. The study sample consisted of 144 undergraduate and graduate counseling students from four Jordanian state universities, and 14 supervisors of these students. Results of multiple regression analyses showed that from the viewpoint of the trainees, goals in the supervisory working alliance were the predictor of their counseling self-efficacy, and explained $11 \%$ of the variation in selfefficacy. In addition, supervisors' perceptions of the trainees' counseling self-efficacy, explained $4 \%$ of the variation in their trainees' perceptions of counseling self-efficacy. The study showed that trainees, compared to supervisors, had higher levels of counseling self-efficacy and supervisory working alliance perceptions, with the exception of the emotional bond. Findings highlight the importance of studying the supervisor-supervisee relationship in the context of counseling training programs. Thestudy's results have implications for improving the supervision outcomes and proposals for future studies.

Keywords: Bordin model of supervisory working alliance; counseling self efficacy; supervisors and counsel or trainees.

*jehadala@hu.edu.jo 


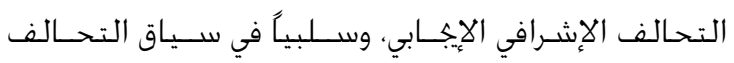

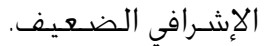

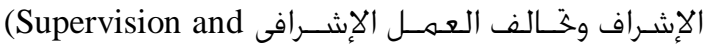
Supervisory Working Alliance) يعرّف الإشـراف في مهنة الإرشـاد بأنه "تـدّخل يقــدم مــن

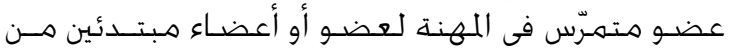

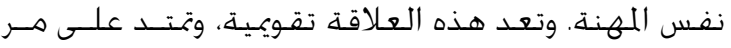

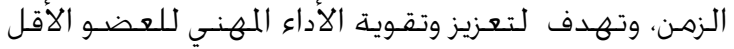

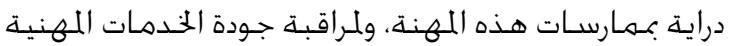

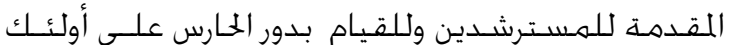

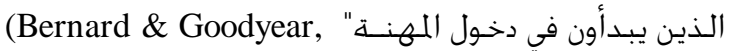

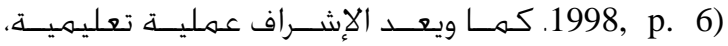

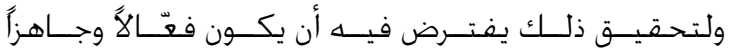

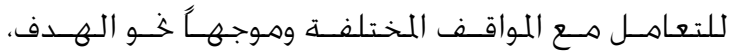

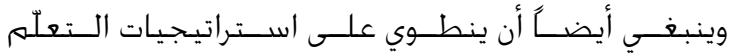

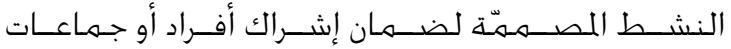

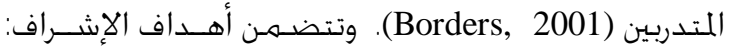

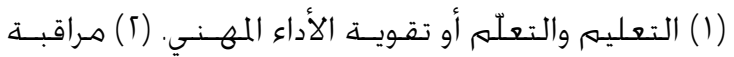

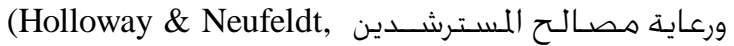

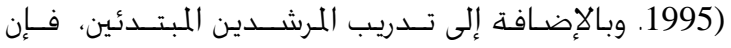

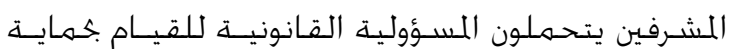

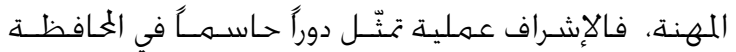

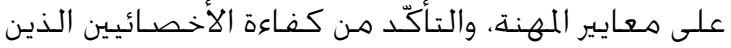

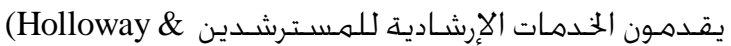
.Neufeldt, 1995; Protivnak, \& Davis, 2008)

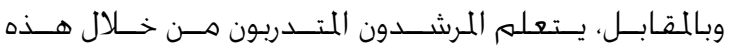

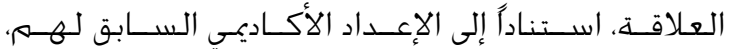

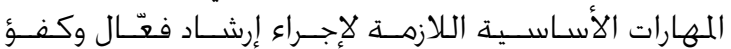

.(Helms \& Cook, 1999)

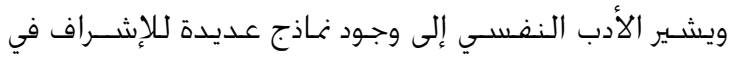

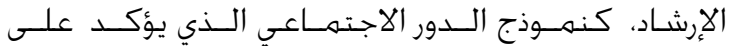

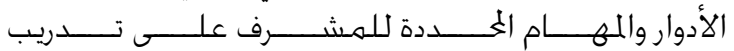

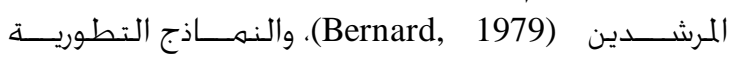
(Stoltenberg, 1981; Stoltenberg \& Delworth, 1987)

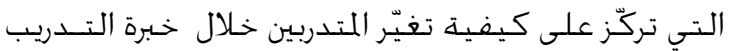

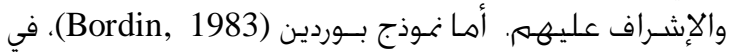

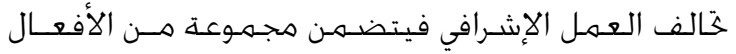

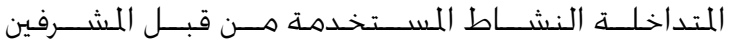

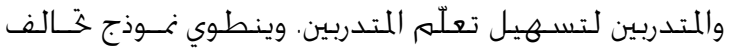

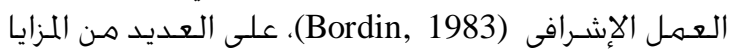

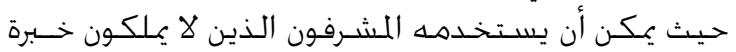

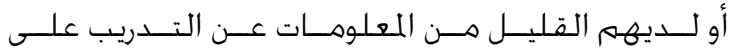

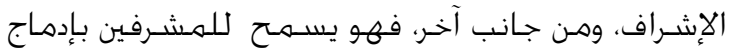
نظريات الإرشاد والإشـراف المختلفة والمتنوعة في عملهم لإنهم

التدريبي (Wood, 2005). (لإنان
يعتبر ختالف العمــل الإشــرافي Supervisory Working) (Alliance) (Bordin, 1983, 1994; Efstation, Patton, من المنظرين الإناف

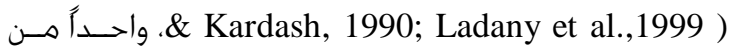

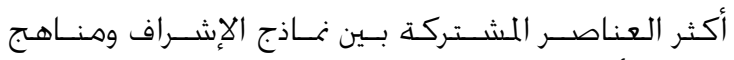

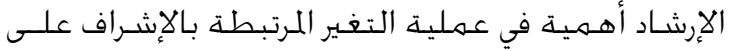

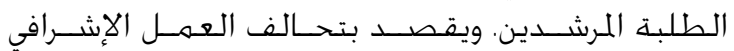

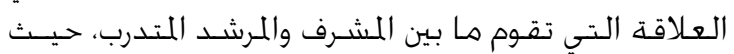

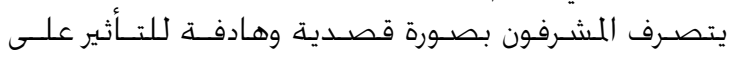

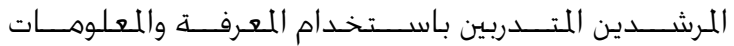

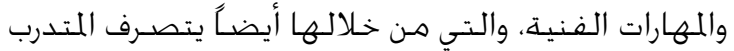

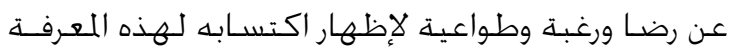

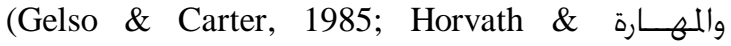
.Greenberg, 1989)

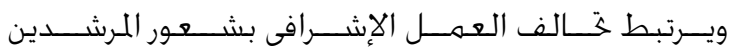
بالفاعليــة الذاتيــة (e.g., Efstation et al., 1990).

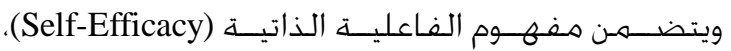

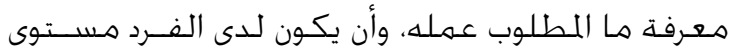

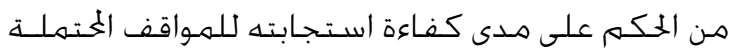

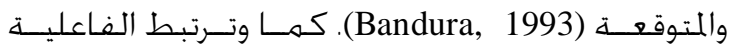

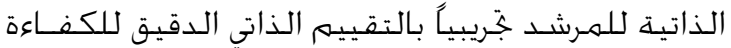

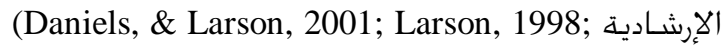
Larson \& Daniels, 1998; Larson, Cardwell, \&

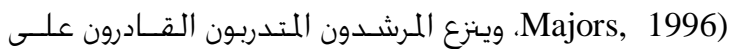

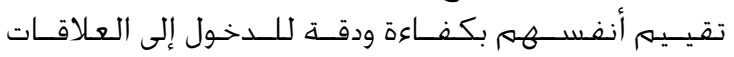

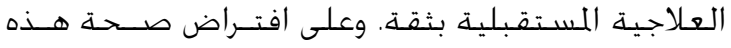

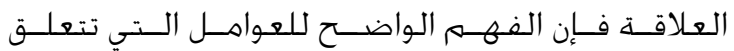

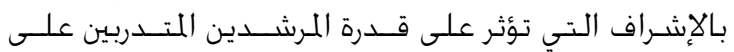

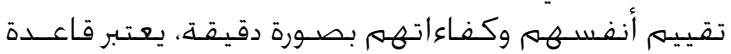
أسـاسية وإلزاميــة (Steward, Breland, \& Neil, 2001).

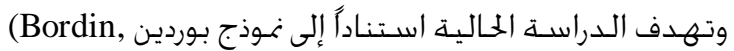

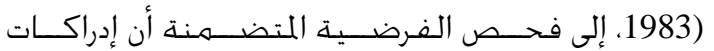

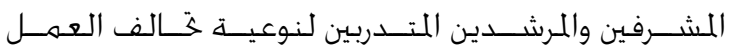
الإشــرافي (Supervisory Working Alliance)، ســنتنبأ

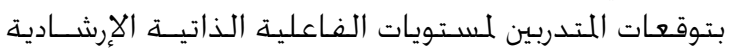

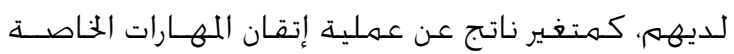

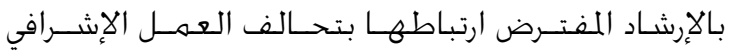

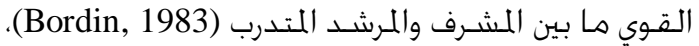

(Bordin, 1979, 1983; وذلك استنادًا إلى أنه في الإشـراف

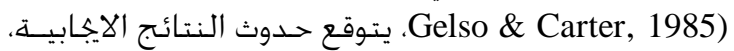

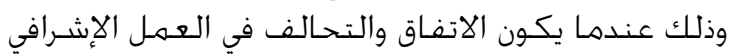

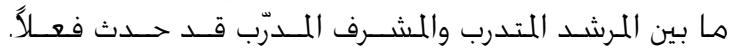

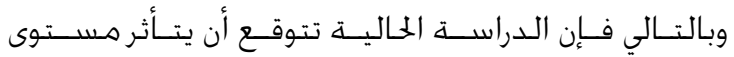

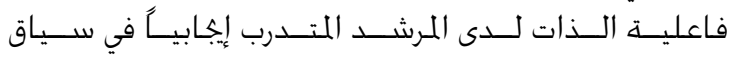




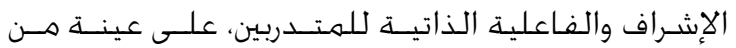

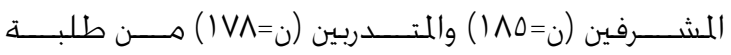

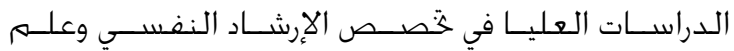
النفس الإكلينيكي المسـجلين في مادة التــدريب العـمـلـي

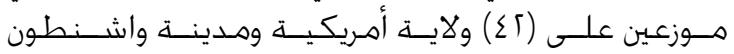

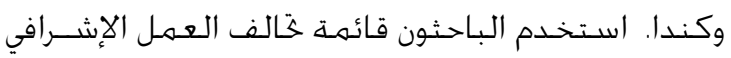

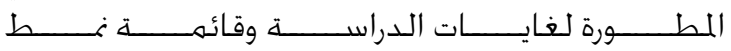

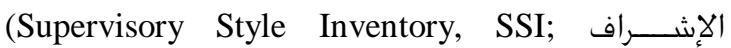
Friedlander \& Ward, 1984) الذاتية \& Self-Efficacy Inventory, SEI; Friedlander (أشـارت نتـائج التحليـلـ الإســكشـافي

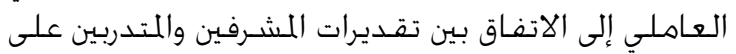

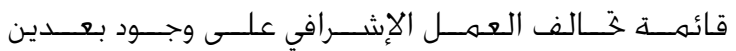

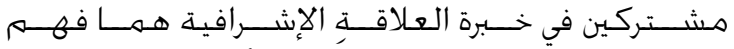

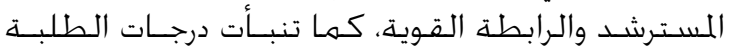

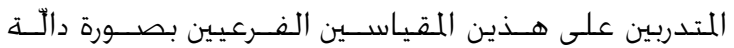

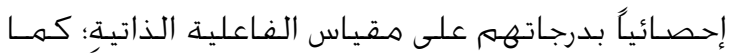

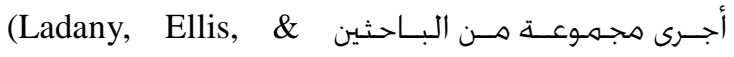

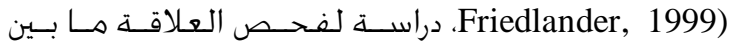

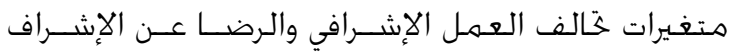

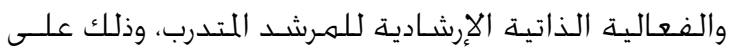

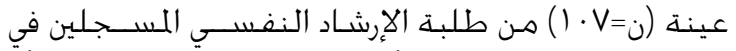

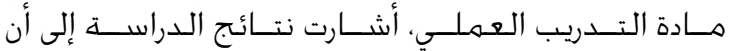

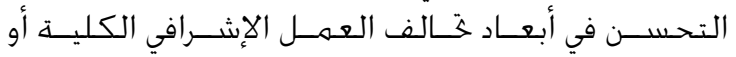

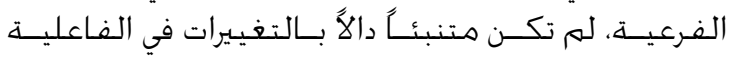

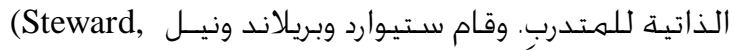
(Breland, \& Neil, 2001)

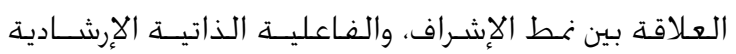

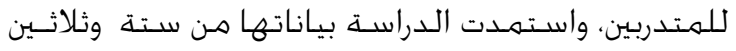

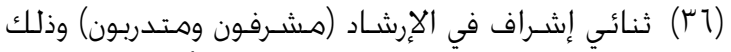

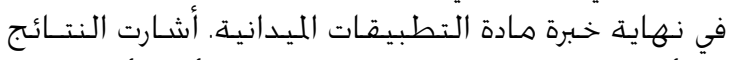

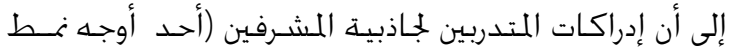

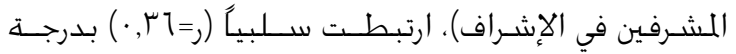

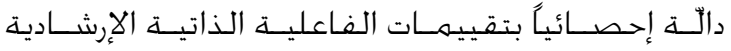

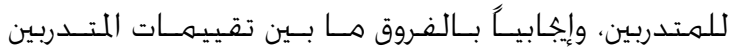

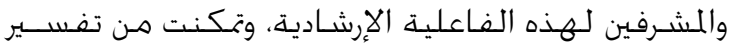

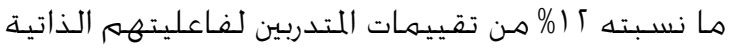

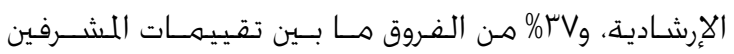

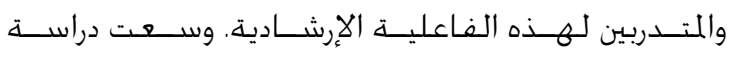

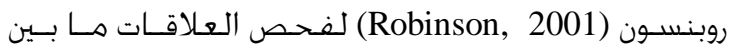

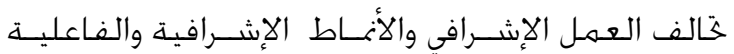

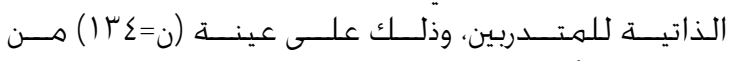

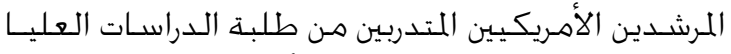

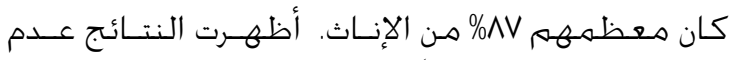

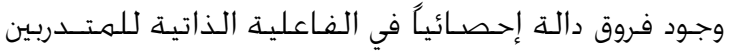

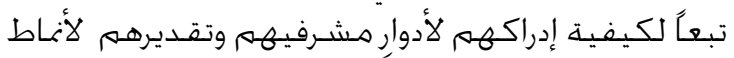

(Counseling Self- الفـاعليــــة الذاتيــــة الإرشــــادية

Efficacy)

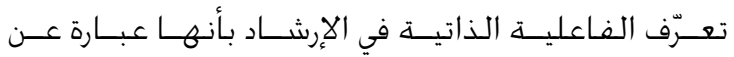

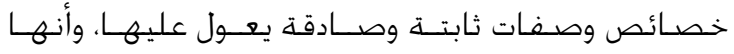

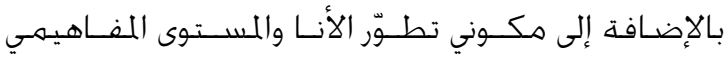

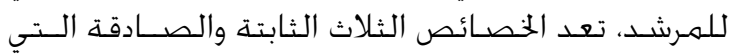

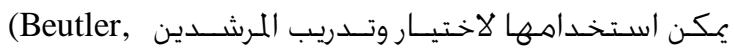
(Bandura, ويرى باندورا Machado, \& Neufeldt, 1994) (1991, p.257)

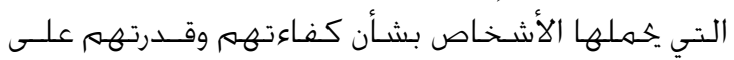

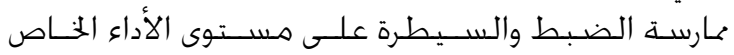

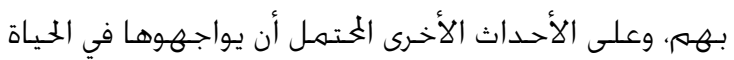

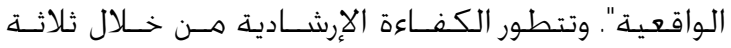

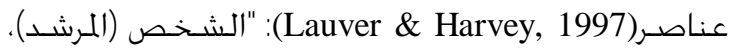

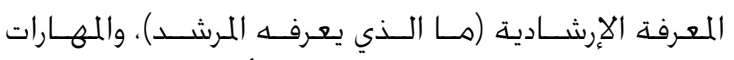

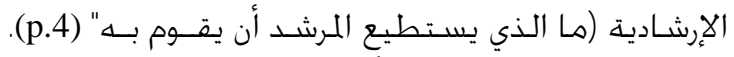

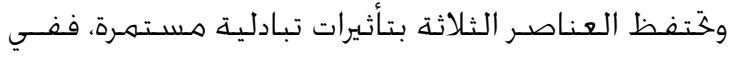

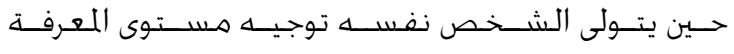

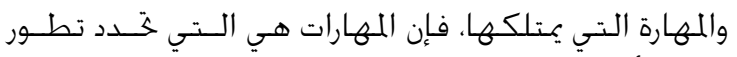

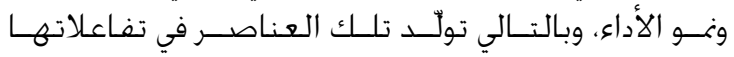

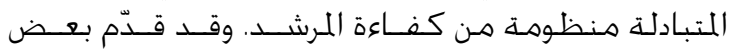
الباحثين (Stolenberg \& Delworth, 1987)، تفسيراً آخر

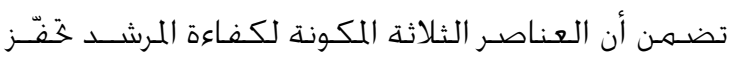

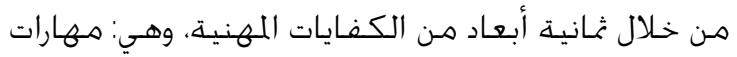

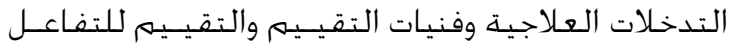

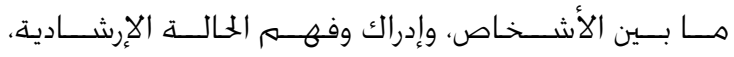

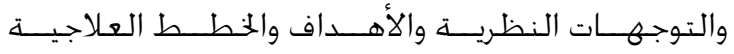

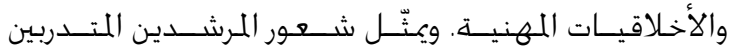

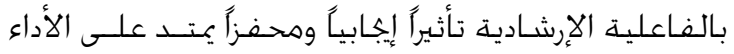

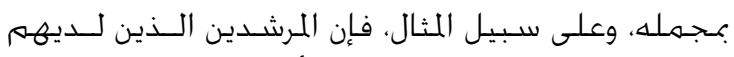

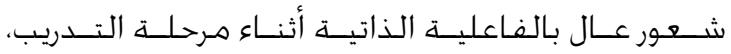

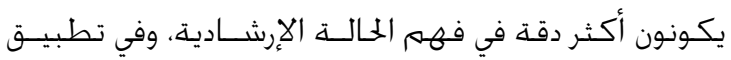

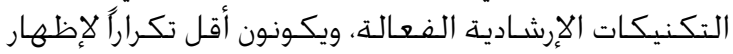

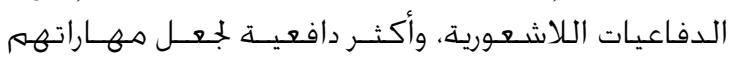

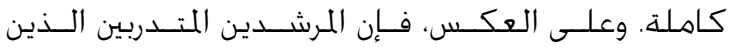

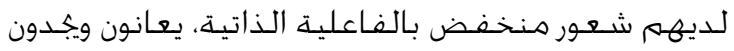

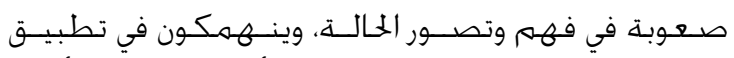

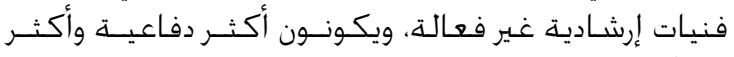

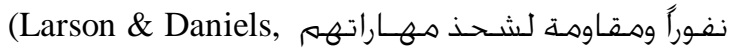
.1998)

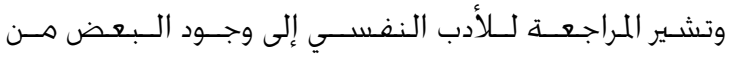

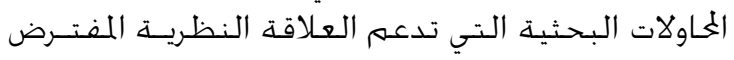

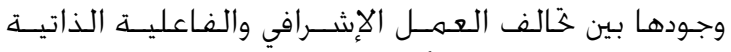

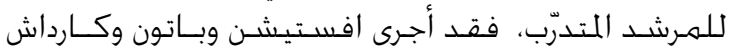
(Efstation, Patton and Kardash, 1990)

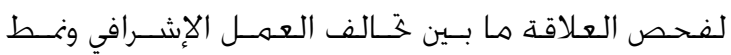




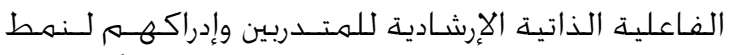

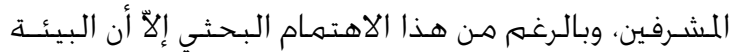

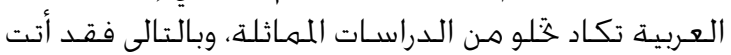

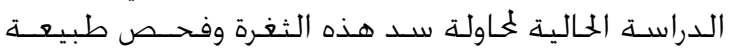

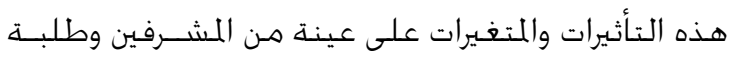
الإرشاد المتدربين في الأردن.

\section{مشـكلة الدراســـ وأهـميتها}

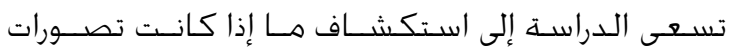

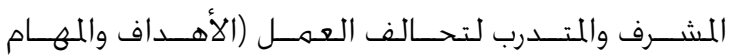

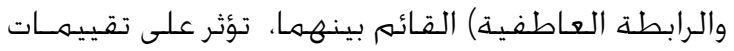

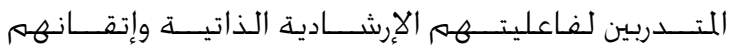

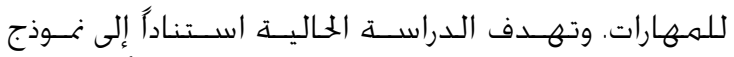

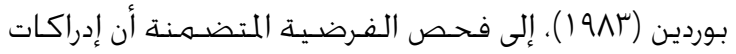

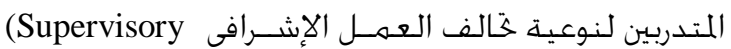
Working Alliance)

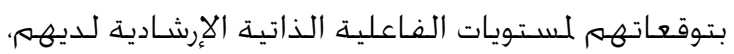

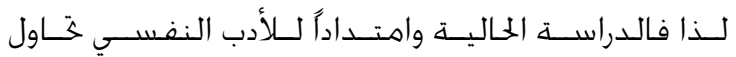
توسيع هذا النهموذج مـن خـلال:

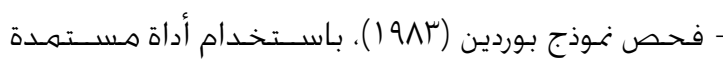

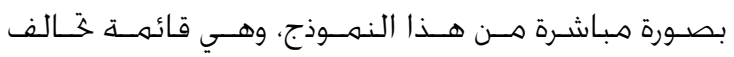

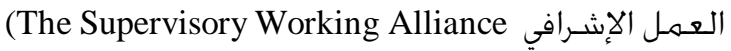
.Inventory; Bahrick, 1990)

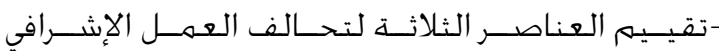

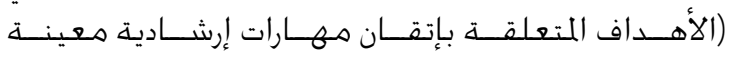

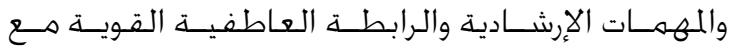

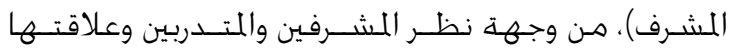
بتوقعات الفاعلية الذاتية للمتـدربين.

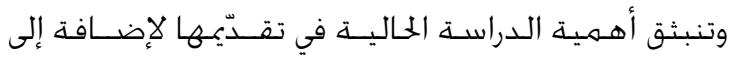

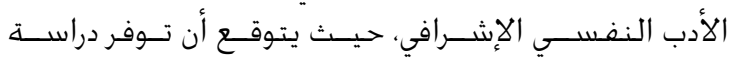

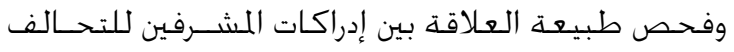

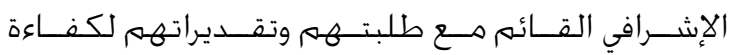

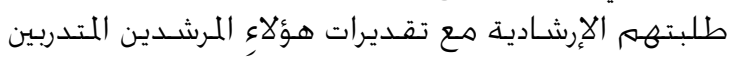

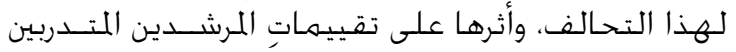

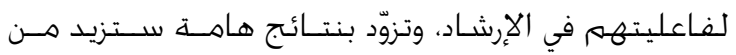

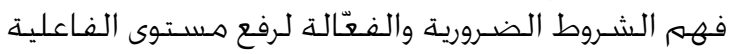

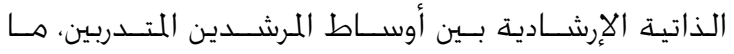

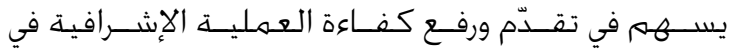

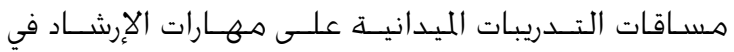

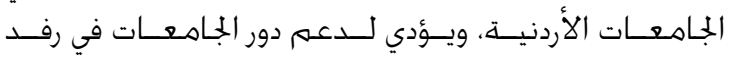

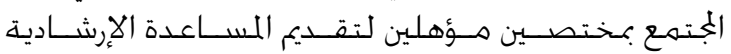

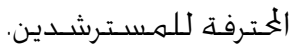

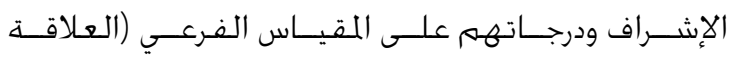
القـوية) لتحـالف العهـل الإثـرافي.

وسـعت حسميدان (Humeidan, 2002) لفحـص العـلاقـات

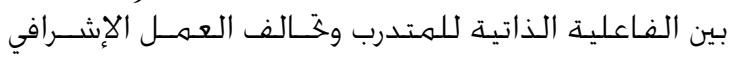

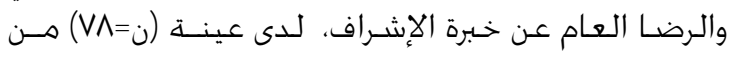

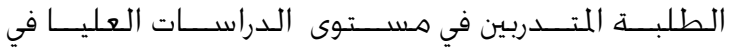

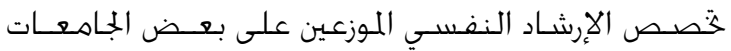

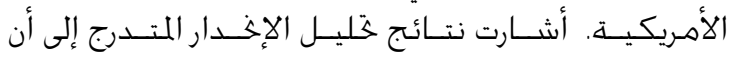

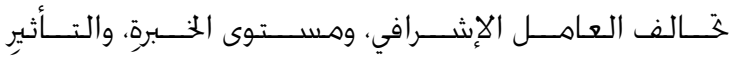

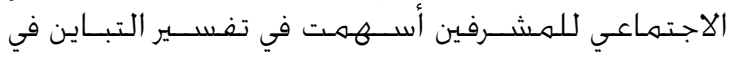

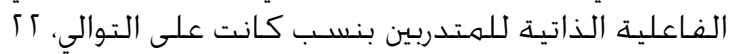

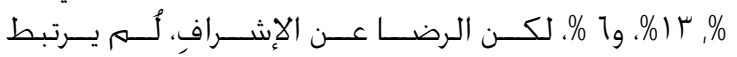

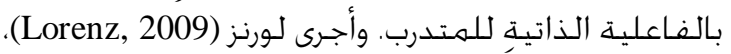

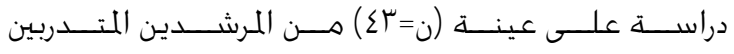

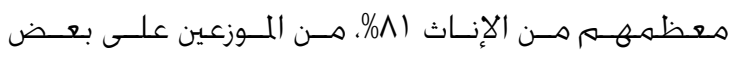

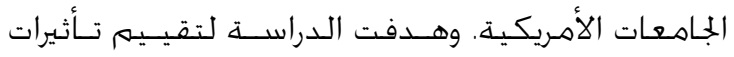

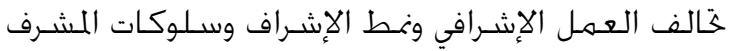

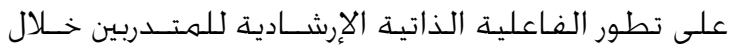

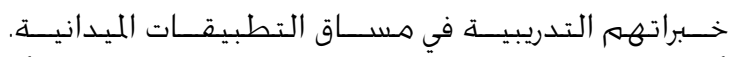

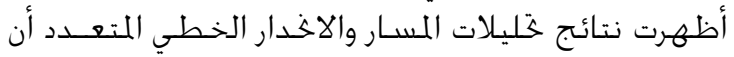

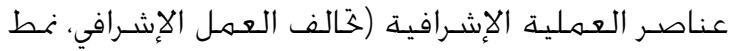

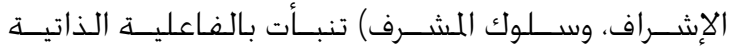

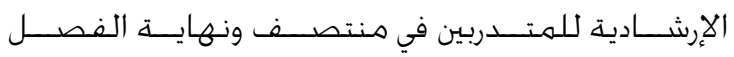

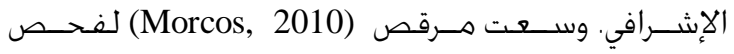

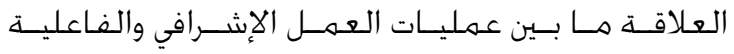

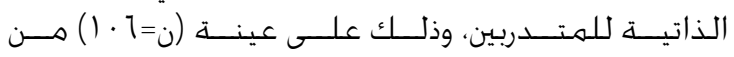

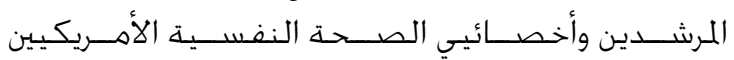

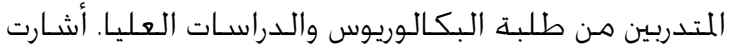

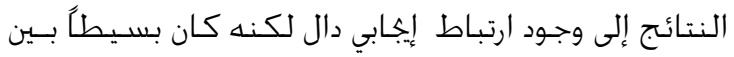

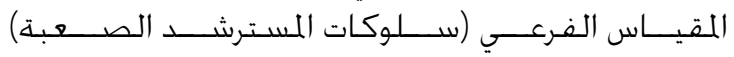

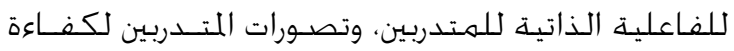

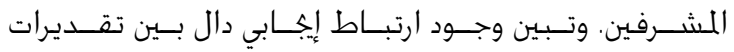

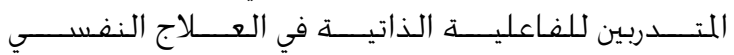

وتصـوراتهـم لقـوة ختالف العـمـل في العـلاقـة الإشـرافيـة. ويظهر الاسـتعراض البحثــي الســابق اهتمــام البـاحثين

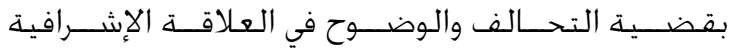

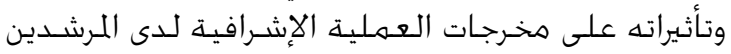

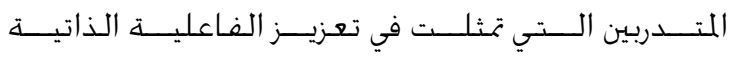

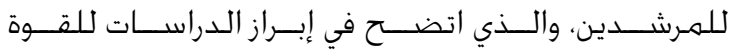

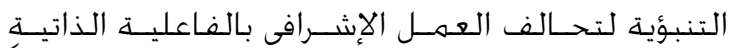
(Efstation et al., 1990; Humeidan, 2002; Lorenz,

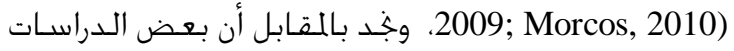

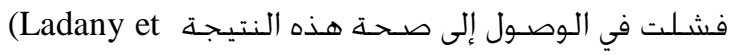

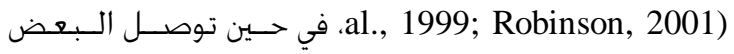

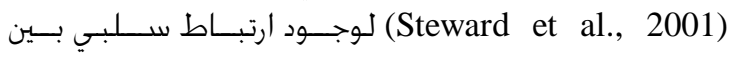


رابطة عاطفية قوية (Strong Emotional Bond)، [ مثالًا.

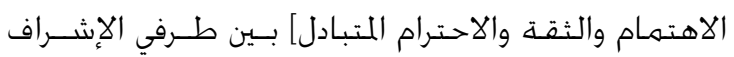

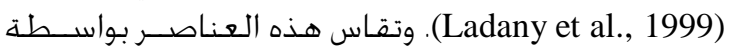

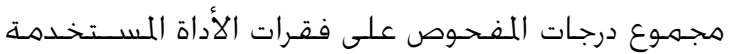

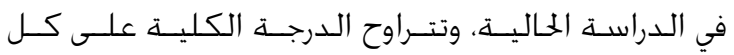

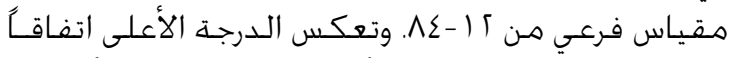

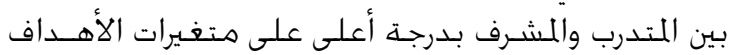
وههمات الإشراف والرابطة العاطفية الأقوى بين الاثنين.

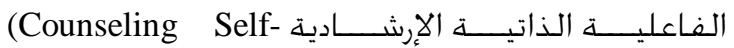
:Efficacy)

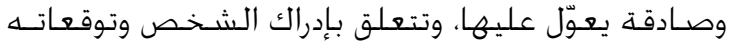
لكفـاءته الإرشادية ولإتقانه للمعارف الإرشـادية وقدرتســ

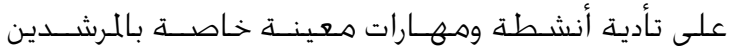

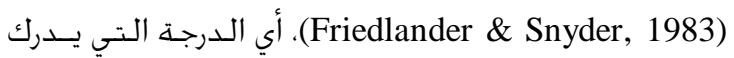

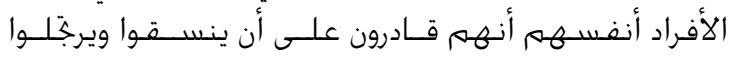

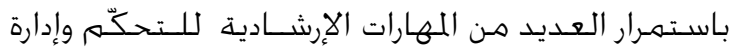

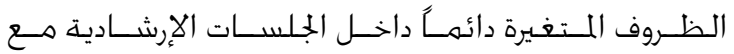

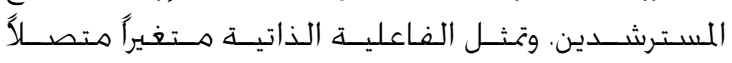

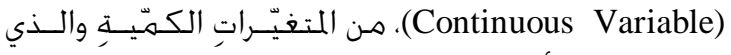

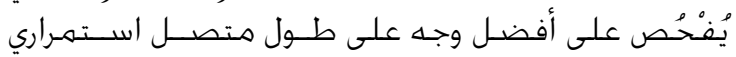

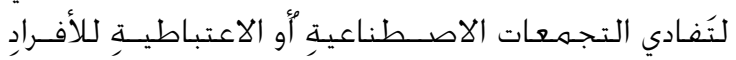

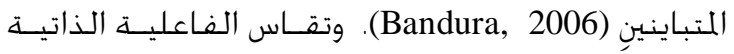

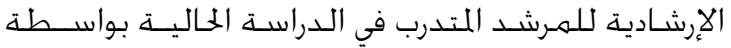

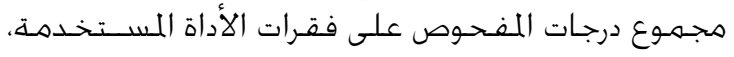

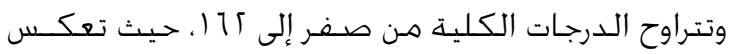

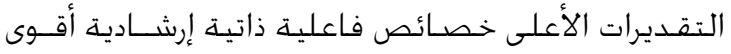
وذلك تبعاً لتقـديراتِ كلٍٍ من المشـرف والمرشـــ المتدرب.

\section{الطريقة والإجـراءات}

\section{مجتمع الدراسـة وعينتها}

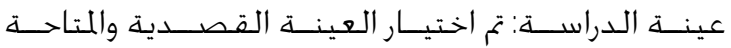

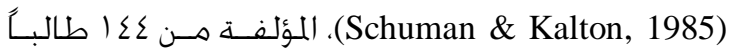

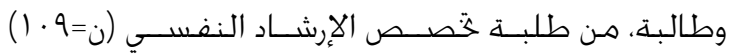

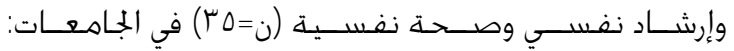

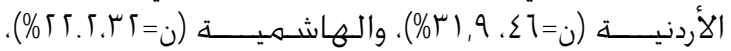

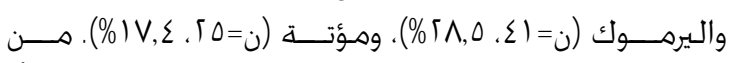

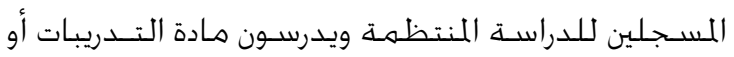

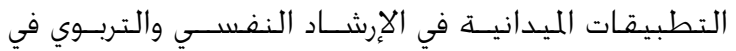

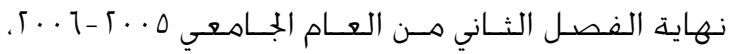

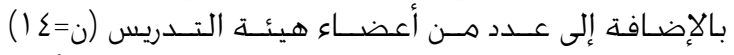

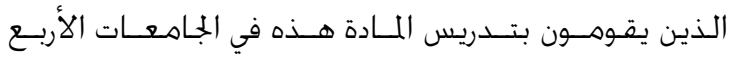

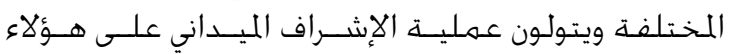

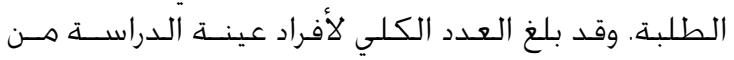

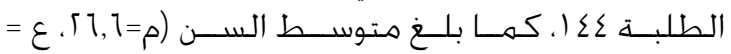

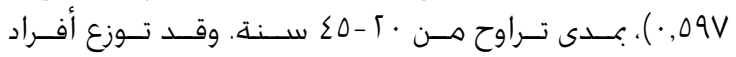

هـدف الدراســـ

تهـدف الدراسـة الحالية لفحص امتــاد مفهـ وم بـوردين

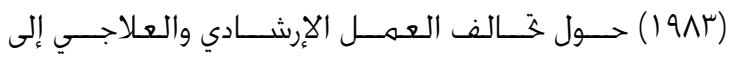

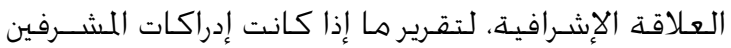

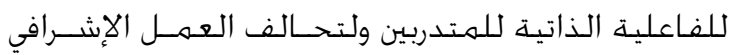

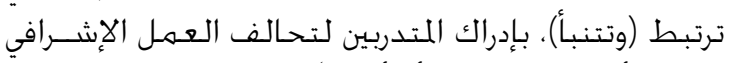

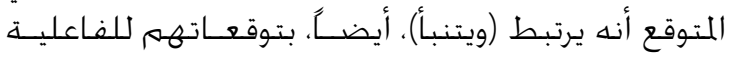

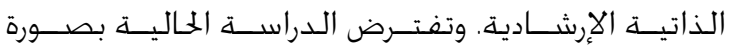

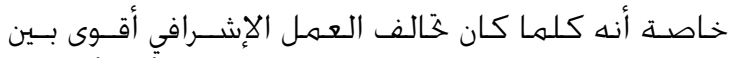

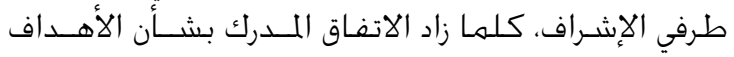

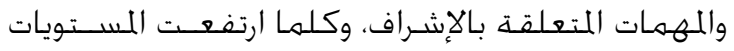

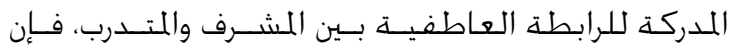

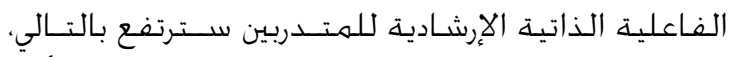

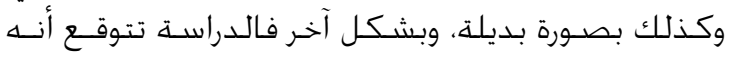

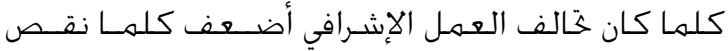

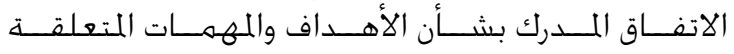

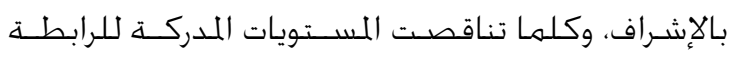

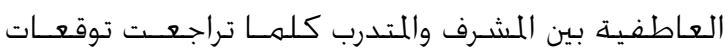
المتدربين لفاعليتهم الذاتية الإرشادية.

أسئلة الدراسـة

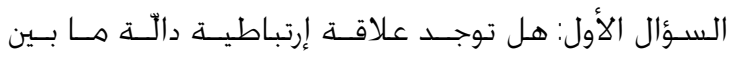

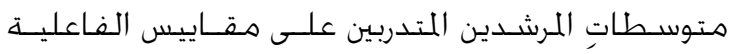

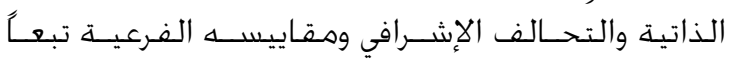

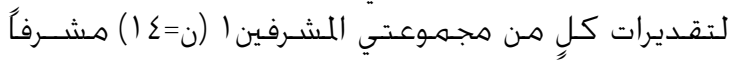

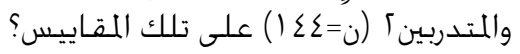

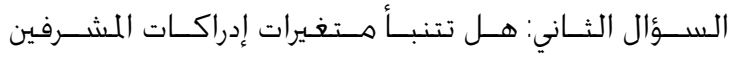

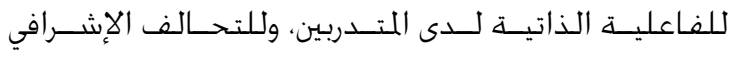

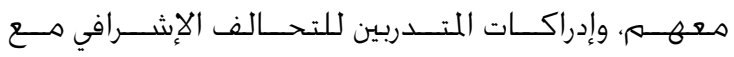

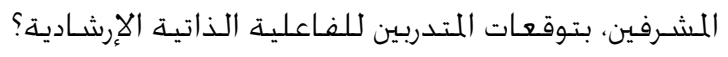

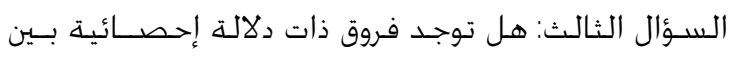

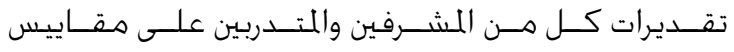

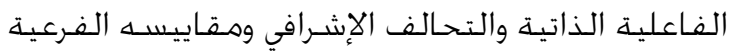

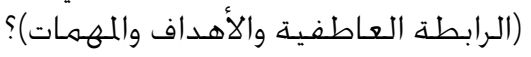

\section{التعريفات الإجرائية للفاهيم ومتغيرات الدراســـ}

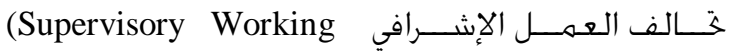

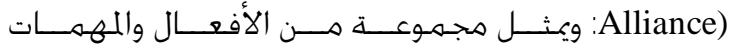

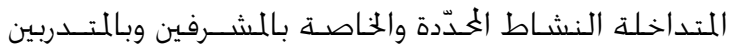

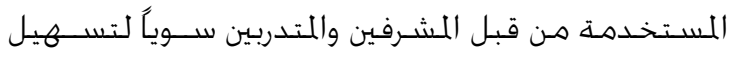

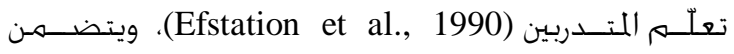

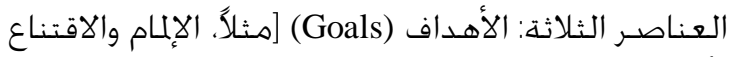

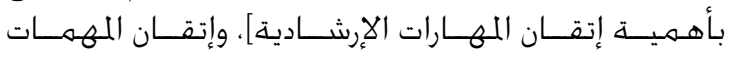

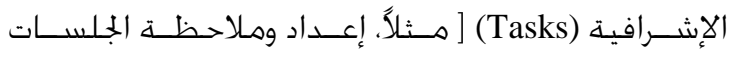

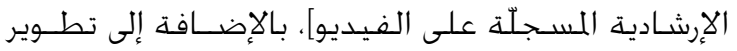


(Ladany et al., 1999) والفاعلية الذاتية (Friedlander) Snyder, 1983)

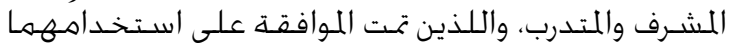

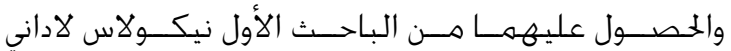

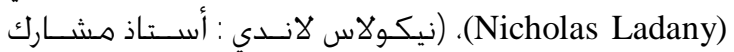

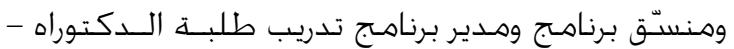

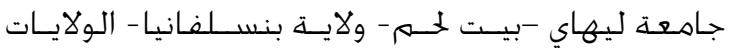

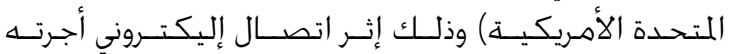

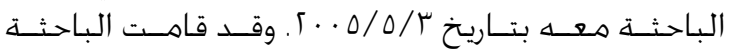

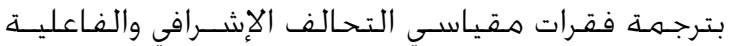

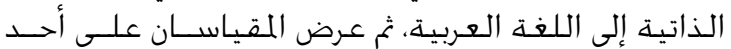

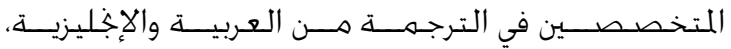

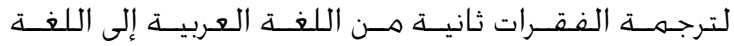

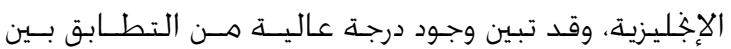

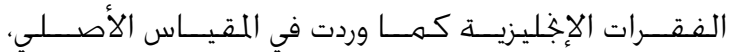

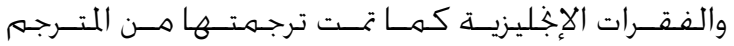

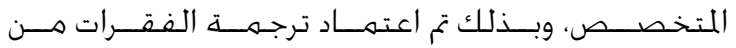

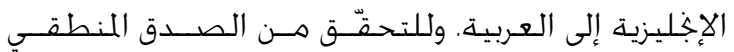

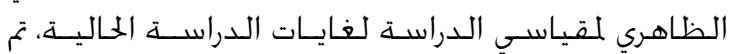

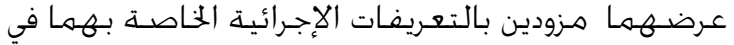

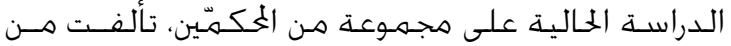

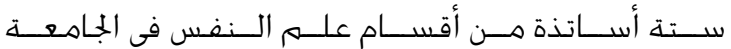

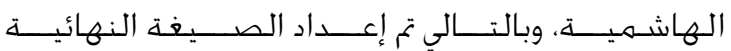

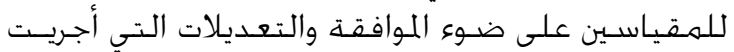

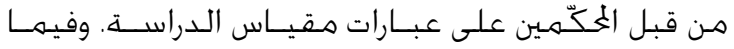

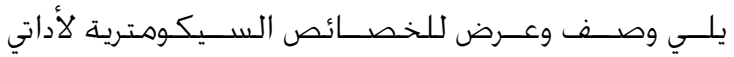

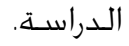

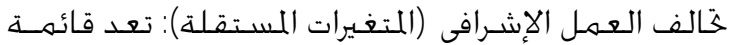

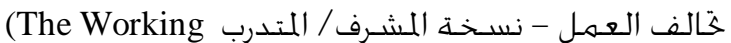
Alliance Inventory-Supervisor / Trainee version [WAI-T]; Bahrick, 1989; Ladany et al., 1999)

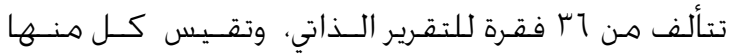

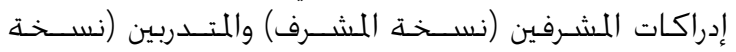

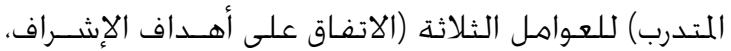

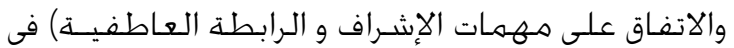

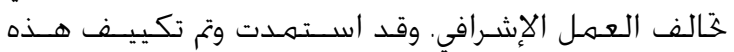

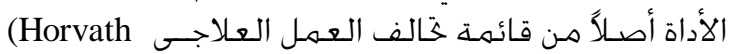

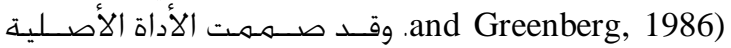

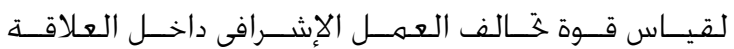

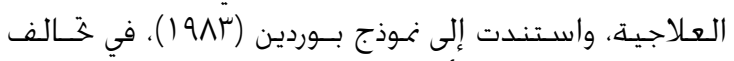

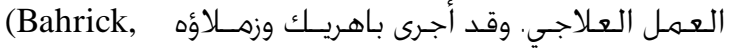
1989; Bahrick, Russell, \& Salmi, 1991)

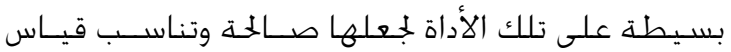

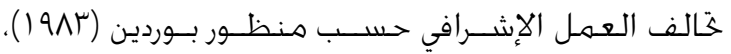

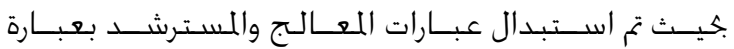

العينة تبعاً للخصائص الديموغرافية والأكاديمية كالتالي:

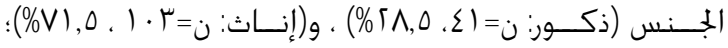

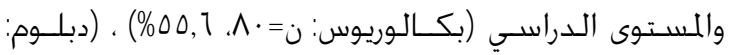

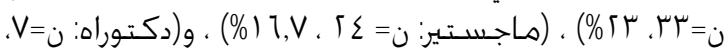

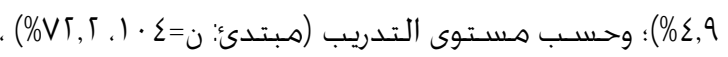

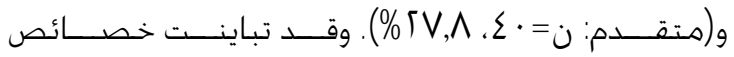

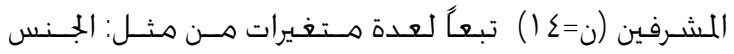

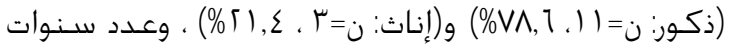

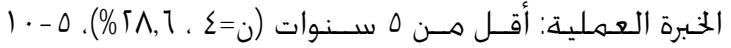

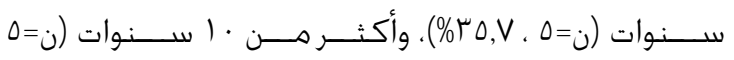

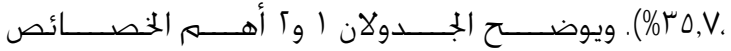

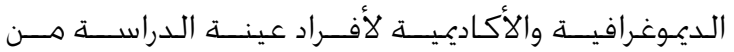

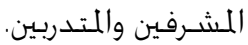

جدول الأوراد

الخصائص الديموغرافية والأكاديمية لأفراد عينة الدراسـة من المشرفين

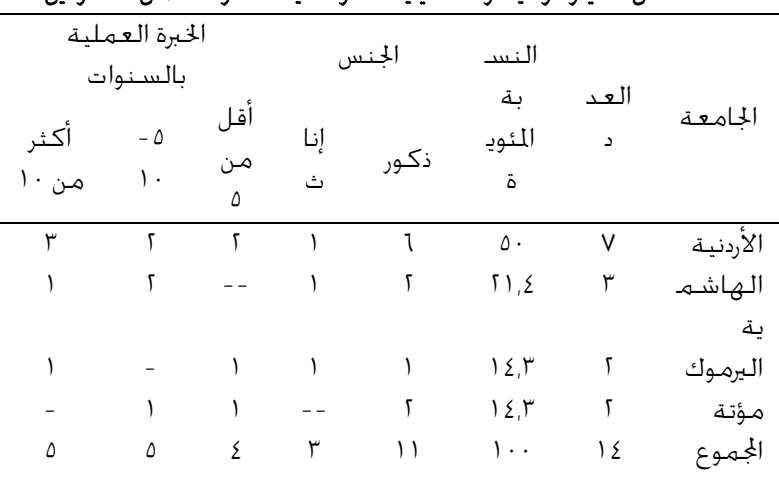

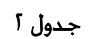

الخصائص الديموغرافبة والأكاديمية لأفراد عينة الدراسة من المتدربين (ن = ع ()

\begin{tabular}{|c|c|c|c|c|}
\hline \multirow{2}{*}{ النسبة المئوية } & \multirow{2}{*}{ العدد } & \multicolumn{2}{|c|}{ الجنس } & \multirow{2}{*}{ الجامعة } \\
\hline & & إناث & ذكور & \\
\hline$r 1,9$ & $\sum 1$ & II & $\Gamma \varepsilon$ & الأردنية \\
\hline$i \tau, \Gamma$ & rr & iV & 0 & الهاشعية \\
\hline$\lceil\wedge, 0$ & ¿1 & $r \Lambda$ & $r$ & الليرموك \\
\hline$I V, \Sigma$ & ro & 11 & 9 & مؤتة \\
\hline $1 \ldots$ & $1 \varepsilon \varepsilon$ & $1 . r$ & ¿1 & الكلي \\
\hline$\varepsilon, 9$ & v & - & v & الدكتوراه \\
\hline $17, \mathrm{~V}$ & $i \varepsilon$ & 11 & 1 & ماجستير \\
\hline 17,9 & $r \mu$ & iV & 1 & دبلوم \\
\hline 00,1 & $\Lambda$. & $\Delta \Lambda$ & it & بكالوريوس \\
\hline $1 \ldots$ & $1 \leq \varepsilon$ & $1 . r$ & $\sum 1$ & الكلي \\
\hline $01, r$ & $\wedge 1$ & & & r.,99- $\Gamma$ \\
\hline$\sum \pi, \Lambda$ & $\pi$ & & & $\varepsilon-r$ \\
\hline $1 \ldots$ & $1 \leq \varepsilon$ & & & مستوى التدريب \\
\hline $\mathrm{V} T, r^{\prime}$ & $1 \cdot \varepsilon$ & & & مبتدئ \\
\hline$\Gamma \mathrm{V}, \Lambda$ & $\varepsilon$. & & & متقدم \\
\hline $1 .$. & $1 \leq \varepsilon$ & & & الكلي \\
\hline
\end{tabular}

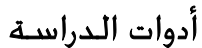

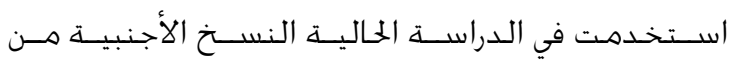

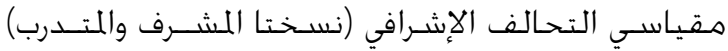




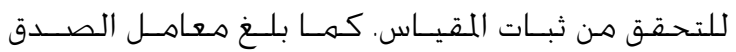

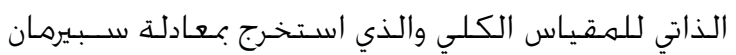

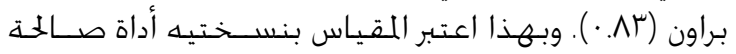

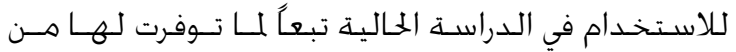

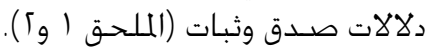

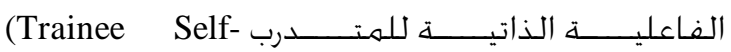
(المتغير التابع): تعتبر قائهــة الفاعليـة الذاتيـة (The Self-Efficacy Inventory [SEI, Friedlander \&

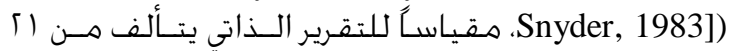

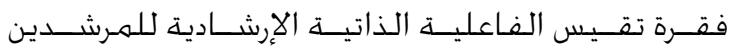

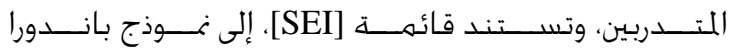

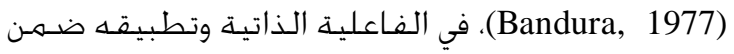

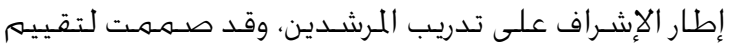

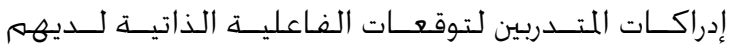

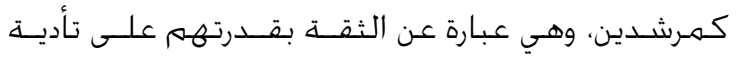

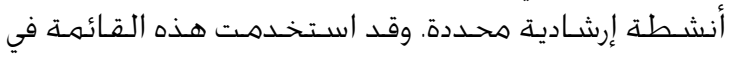

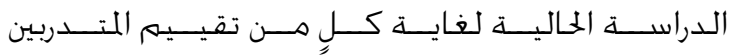

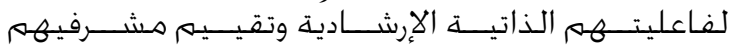

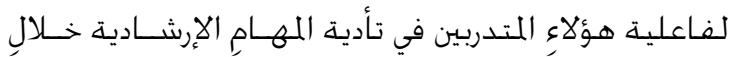

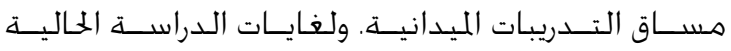

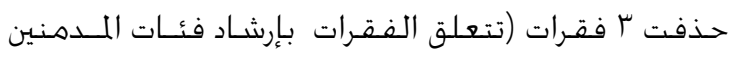

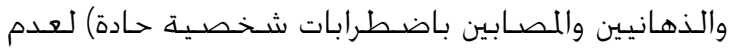

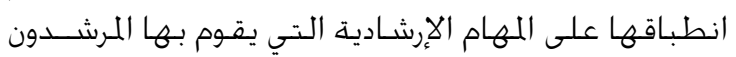

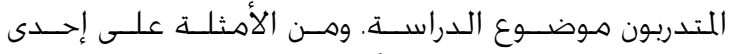

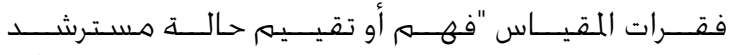

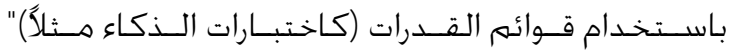

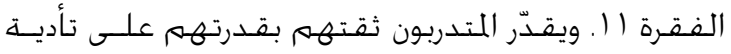

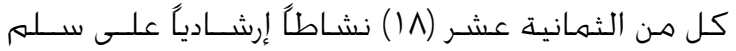

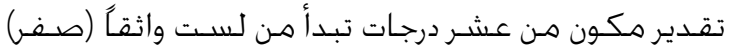

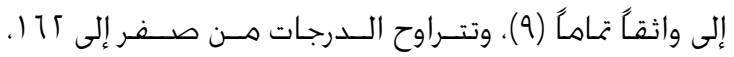

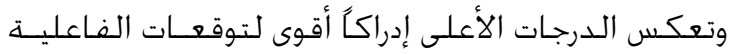

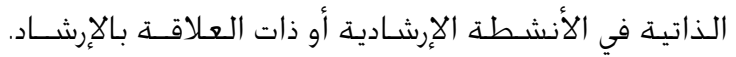

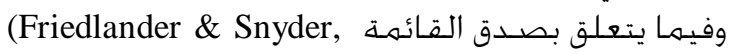

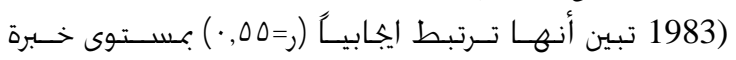

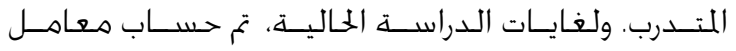

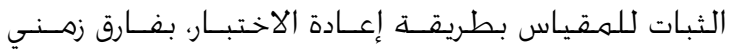

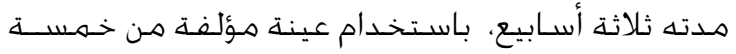

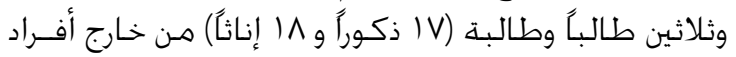

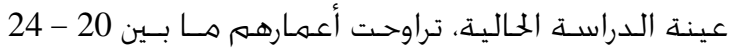

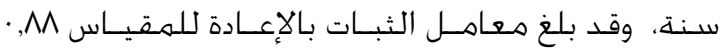

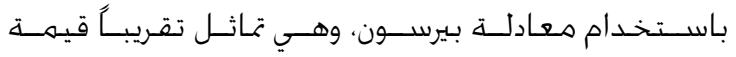

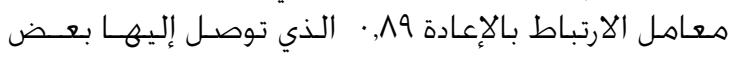

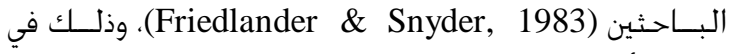

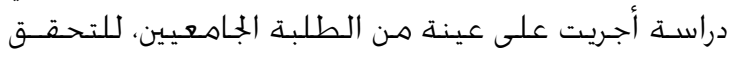

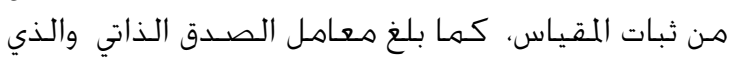

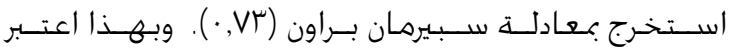

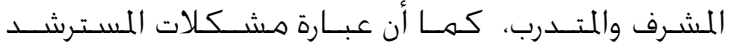

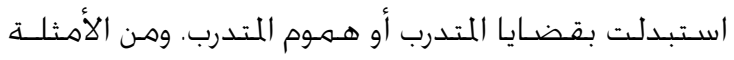

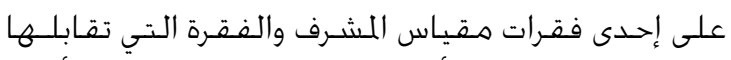

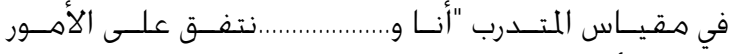

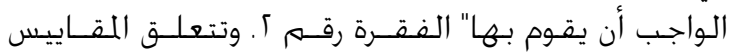

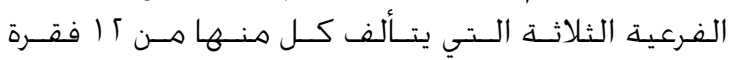

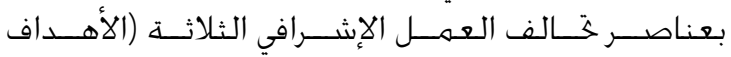

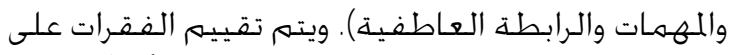

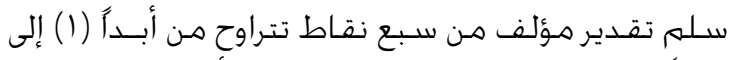

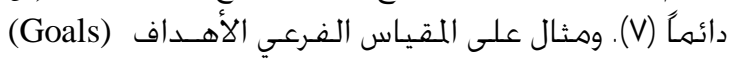

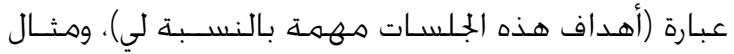

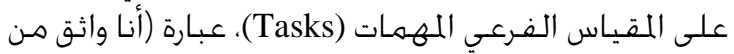

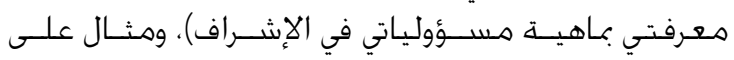
المقياس الفرعي للرابطة العاطفية (Emotional Bond)،

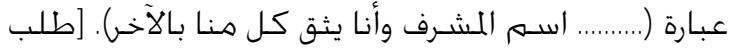

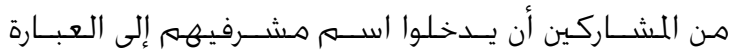

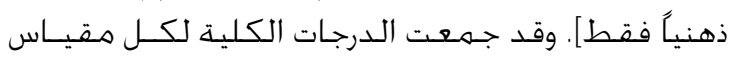

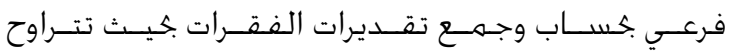

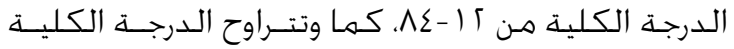

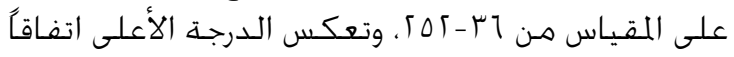

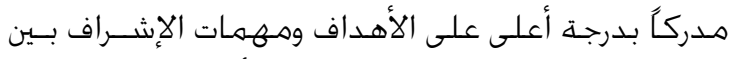

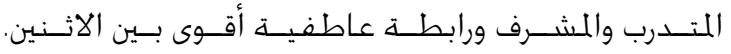

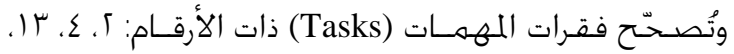

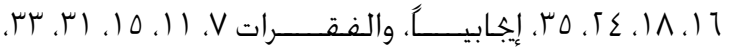

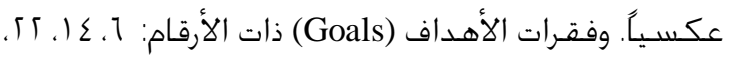

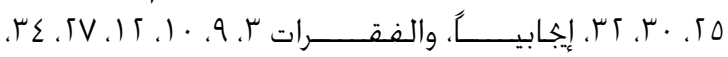

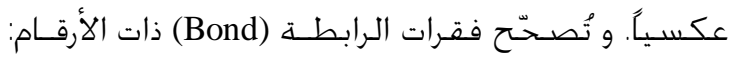

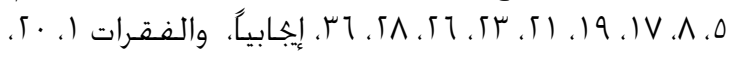
(9)

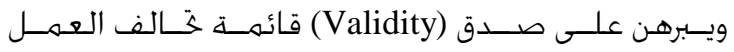

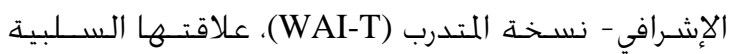

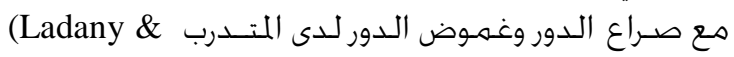

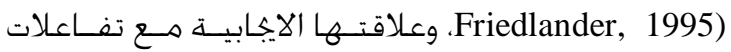

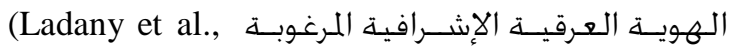

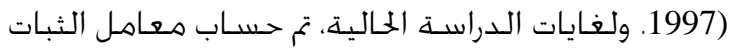

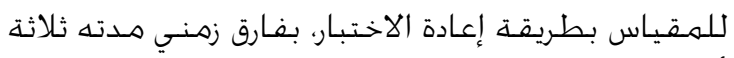

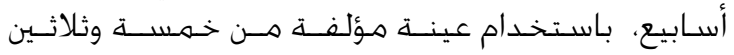

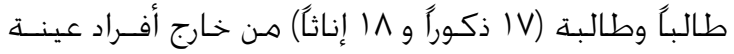

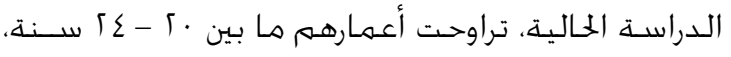

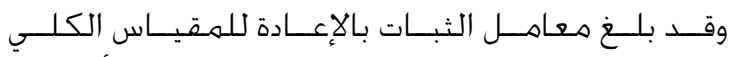

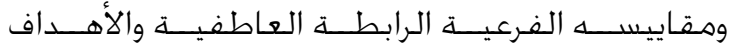

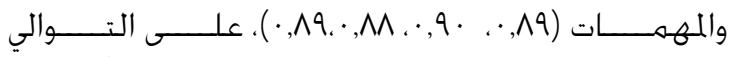

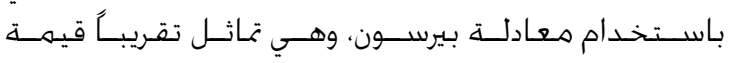

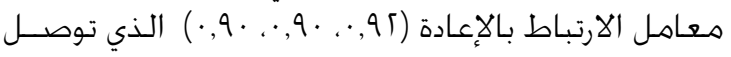

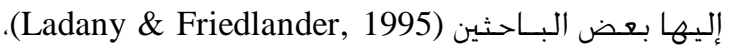
وذلك في دراسـة أجريت على عينة من الطلبة الجـامعيين. 
الإحصـائي ع乏 ا استبانة معبأة من المتدربين ومثلــها مـن

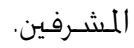

\section{المعالجة الإحصائية للبيانات}

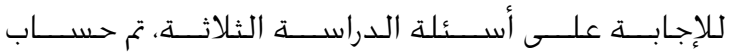

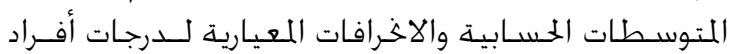

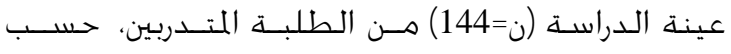

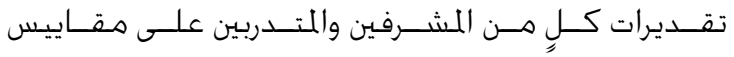

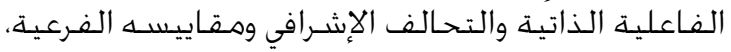

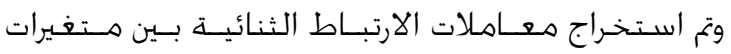

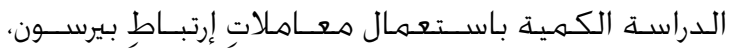

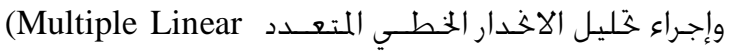
(Regression)

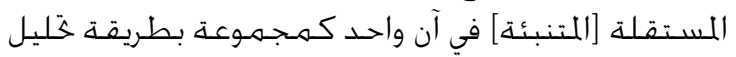

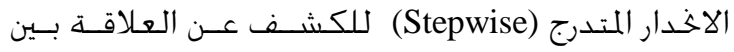

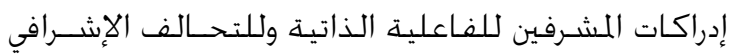

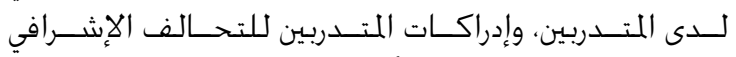

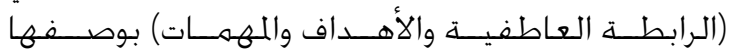

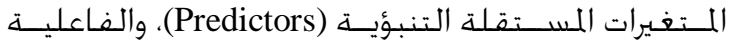

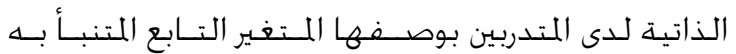

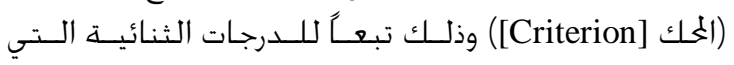

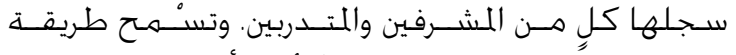

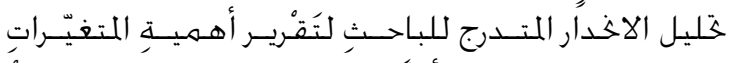

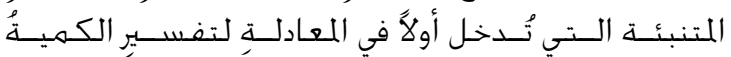

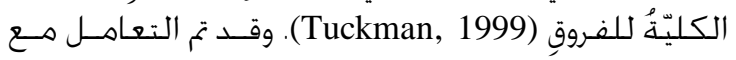

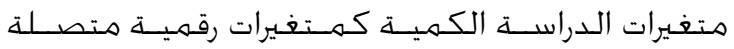

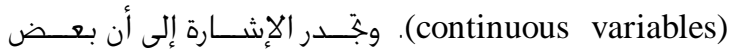
الباحثين (Ladany \& Malouf, 2010, p. 573) في مجال

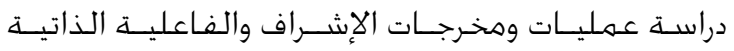

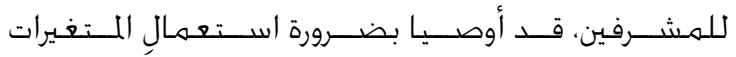

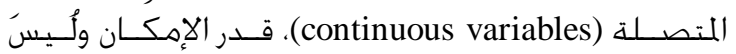

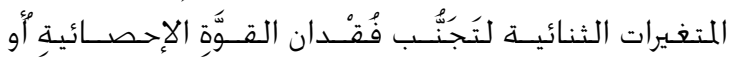

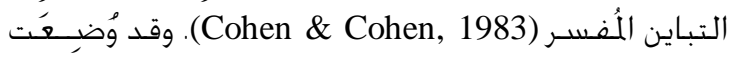

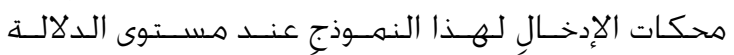

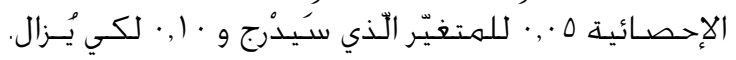

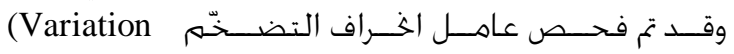

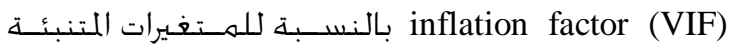

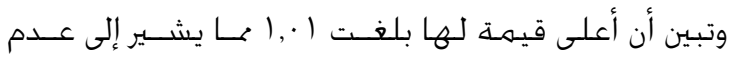

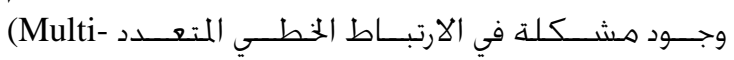

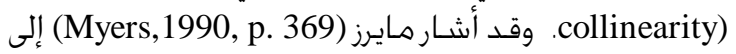

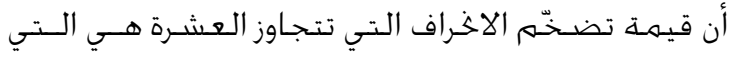

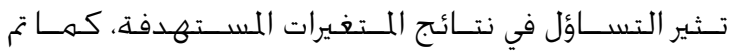

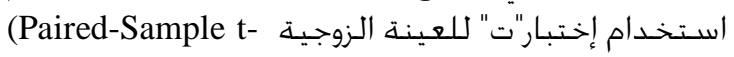

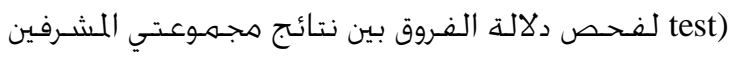

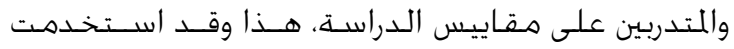

المقياس أداة صـالحة للاستخـدام في الدراسـة الحالية، تبعاً لما توفرت لها من دلالات صدق وثبات (الملحق با). إجراءات تطبيق الأدوات وجهمع البيانات دلات لهات

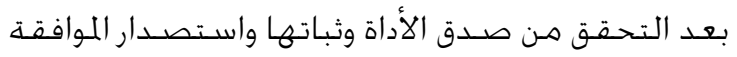

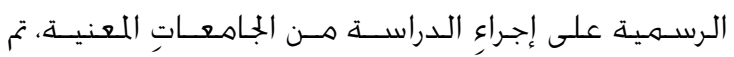

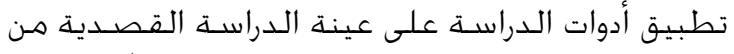

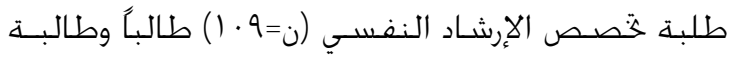

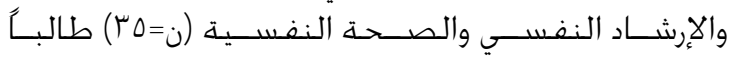

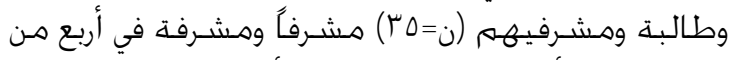

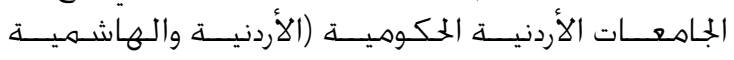

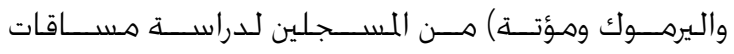

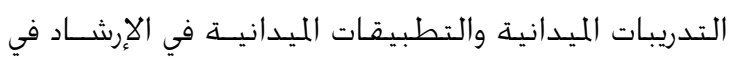

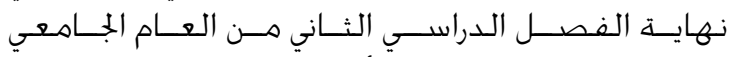

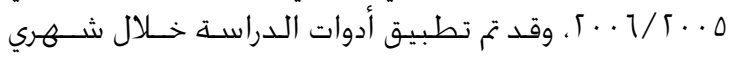

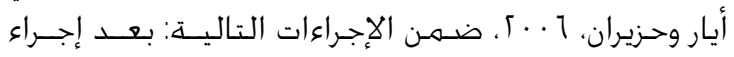

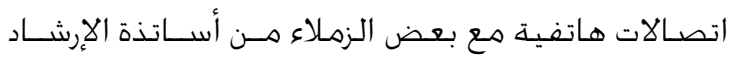

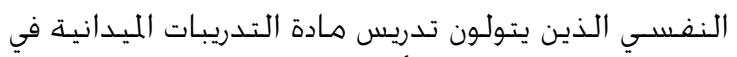

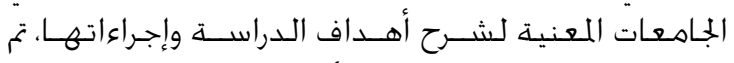

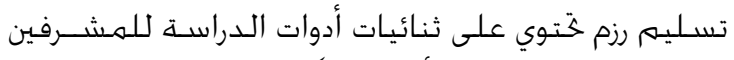

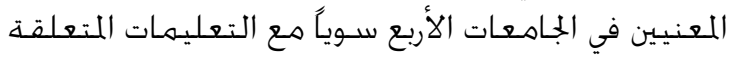

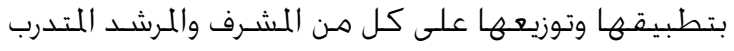

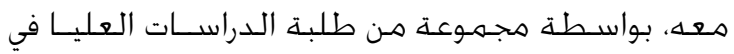

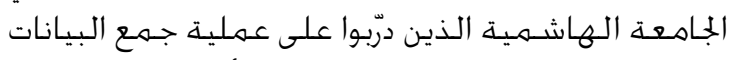

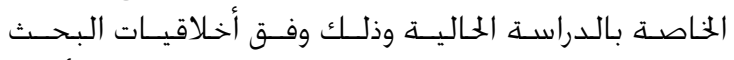

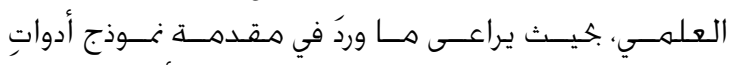

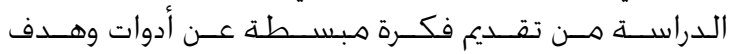

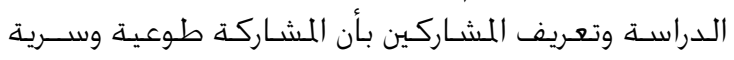

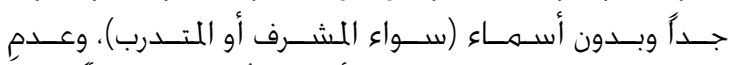

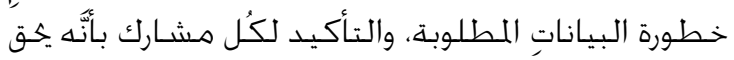

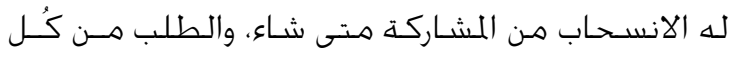

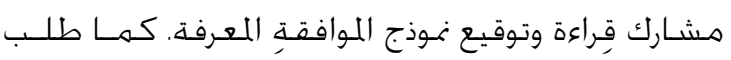

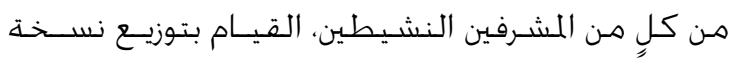

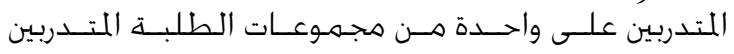

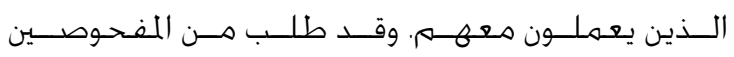

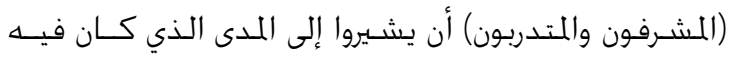

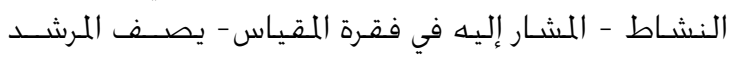

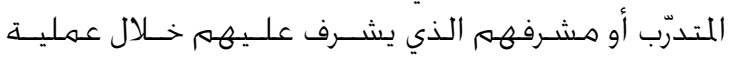

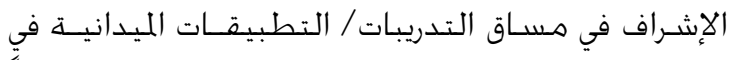

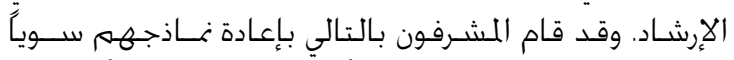

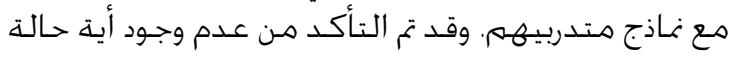

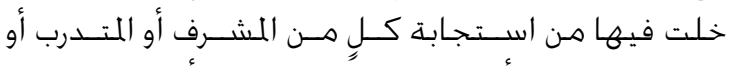

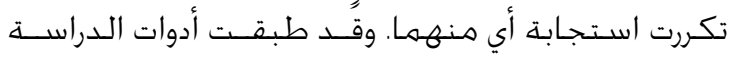

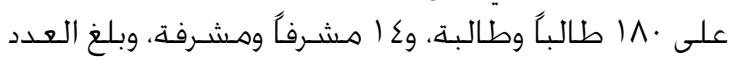

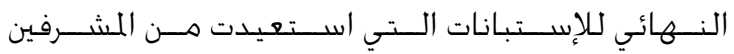

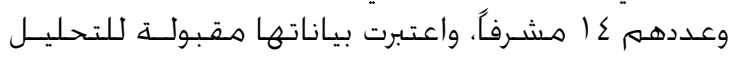


الفـاعلية الذاتية والتحالف الإشـرافي ومقـاييســـ الفـرعيـة

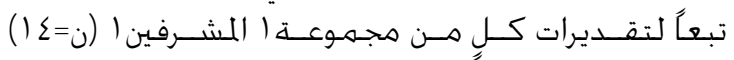

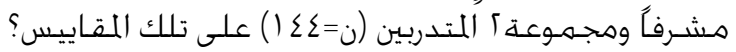

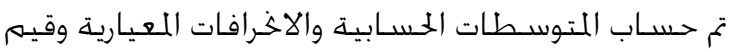

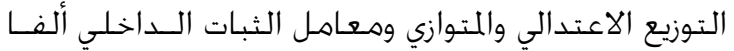

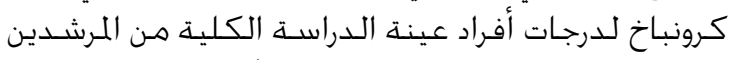

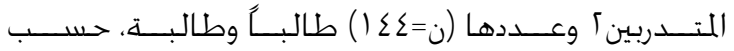

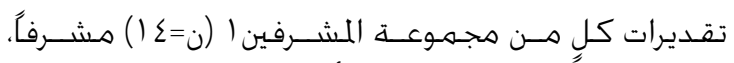

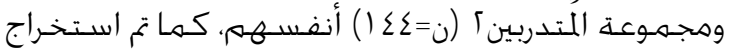

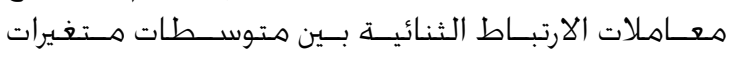

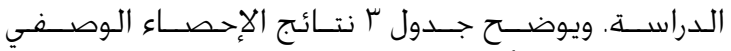

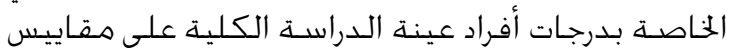
الدراسـة الكلية والفـرعية.

ويلاحظ من البيانات الواردة في جدول r أن قيم التوزيع

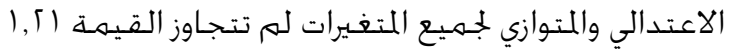

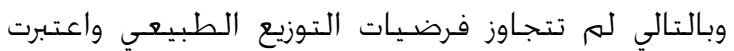

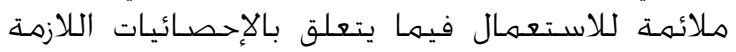
لغايات الـراســ (Tabachnick \& Fidel, 2001). كما ويوضح جدول ع مصفوفة الارتباط الثنائية

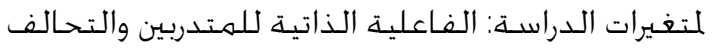

رزهة البراهـج الإحســائية للعلوم الاجــماعيـة (SPSS) في خليل بيانات هـذه الدراسـة.

$$
\text { محددات الدراسـة }
$$

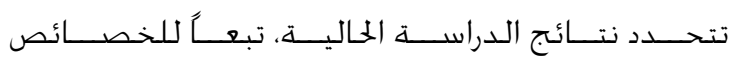

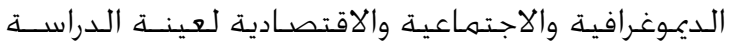

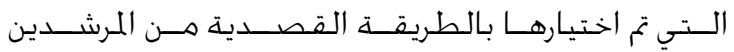

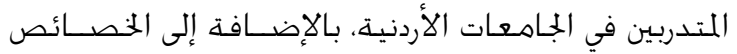

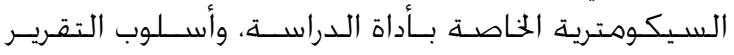

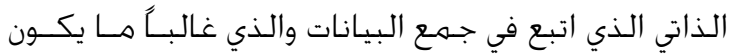

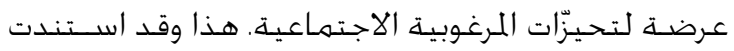

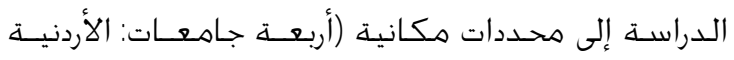

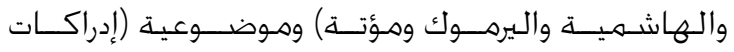

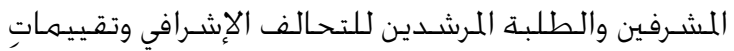

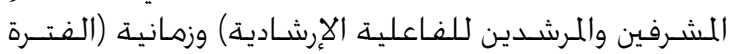

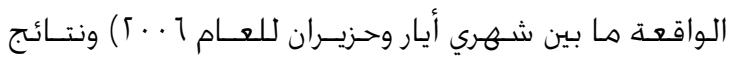

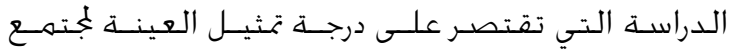
الـدراســة.

\section{نتائج الدراسـة ومناقشـهـا}

للإجـابة على السـؤال الأول: هـل توجـد علاقة ارتباطيـة دالّة

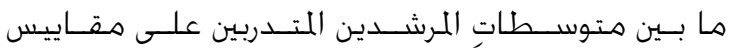

جدول r ن بs

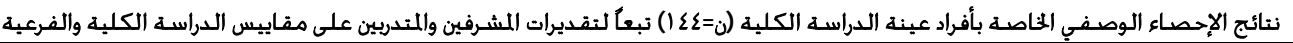

\begin{tabular}{|c|c|c|c|c|c|c|}
\hline ألفا كرونباخ (a) & $\begin{array}{l}\text { التفـرطح } \\
\text { Kurtosis }\end{array}$ & $\begin{array}{c}\text { الالتواء } \\
\text { Skewness }\end{array}$ & المدى & الالعخراف & المتوسط & المقياس \\
\hline & & & & & & المشـرفون' \\
\hline$\cdot, 91$ & $\cdot, \wedge \Sigma$ & $\cdot, \wedge \vee-$ & $9 \wedge, \Sigma$ & $\cdot, \cdot 1 \Gamma$ & $1 \cdot \cdots, \wedge \mathrm{V}$ & الفاعلية الذاتية (· - > 7 ( ) \\
\hline$\cdot, \wedge \mathrm{V}$ & 1,51 & $\cdot, \Sigma 0-$ & $1 \cdot V, \Lambda$ & 11,01 & $119, \cdot \wedge$ & 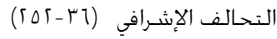 \\
\hline$\cdot, \wedge \Delta$ & $\cdot, 19$ & $\cdot, r$ & $\Sigma \mathrm{V}, \Sigma$ & $\vee, \wedge r$ & or, IV & 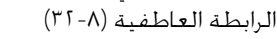 \\
\hline$\cdot, \wedge 1$ & $1, \Gamma \varepsilon$ & $\cdot, \Sigma \mathrm{V}$ & $\Delta \Gamma, r$ & $\vee, \wedge \varepsilon$ & $\sum 9, \cdot 1$ & 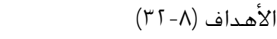 \\
\hline$\cdot, \wedge \mathrm{V}$ & $1, \cdot 9$ & $1, \cdot 1$ & $r q, \varepsilon$ & $\Lambda, \cdot 1$ & $0 \cdot, 10$ & 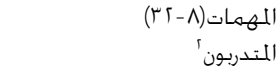 \\
\hline$\cdot, \wedge 9$ & $\cdot, 71$ & $\cdot, \wedge \Delta-$ & $\mathrm{V} \wedge, r$ & IV,IT & $1 \cdot \varepsilon, 9$. & الفاعلية الذاتية (· - [ 7 ( ) \\
\hline$\cdot, \wedge)$ & • ז & $\cdot, 7 \%-$ & $1 \Gamma \varepsilon, V$ & 14,90 & $1 \Gamma r, r \Lambda$ & 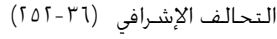 \\
\hline$\cdot, \mathrm{V} \wedge$ & $\cdot, 11$ & $\cdot, 09-$ & $\Delta \mathrm{V}, \mathrm{O}$ & $11, \mathrm{Vr}$ & $\Delta r, v$. & الرابطة العاطفية (^ - ؟ ) \\
\hline$\cdot, \mathrm{VV}$ & $\cdot, r \Gamma$ & $\cdot, \Gamma \mathrm{V}-$ & $\Delta r, r$ & $1 \cdot, 7$ & $\Delta 1, V$ & 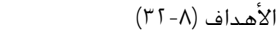 \\
\hline$\cdot, \wedge \varepsilon$ & $\cdot, \Gamma \varepsilon$ & $\cdot, \Gamma \wedge-$ & $\Delta 1,1$ & $1 \cdot, 01$ & $\Delta r, 9 \mu$ & المهمات( \\
\hline
\end{tabular}

جدول

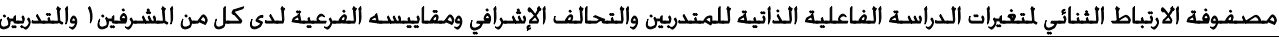

\begin{tabular}{|c|c|c|c|c|c|c|c|c|c|}
\hline \multicolumn{4}{|c|}{ المتدربون } & \multicolumn{5}{|c|}{ المشـرفون ا } & \multirow[b]{2}{*}{ المتغير } \\
\hline$\varepsilon$ & $r$ & 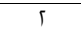 & 1 & 0 & $\varepsilon$ & $r$ & T & 1 & \\
\hline & & & & & & & & & 'المشـرفون' \\
\hline & & & & & & & & $\ldots$ & ا. الفاعلية الذاتية \\
\hline & & & & & & & $-\ldots$ &,$\varepsilon \varepsilon$ & آ. الرابطة العاطفية \\
\hline & & & & & & $\ldots$ & $* *, V \Sigma$ & $*, 1 \wedge$ & "ّ. الأهداف \\
\hline & & & & & $\ldots$ & $* *, 11$ & $* *, 7 \pi$ &,$\cdots 9$ & ع. اللهمات \\
\hline & & & & $\ldots$ & $* *$, Vo & $* *, 95$ & $* *, 9 \mu$ &,$\cdot \mu$ & 0. التحـالف الإشـرافي \\
\hline & & & & & & & & & المتدربون \\
\hline & & & $\cdots$ & $*, \Gamma \cdot \Gamma$ & $\cdot \wedge$ & $*, \Gamma$ & $*, 191$ & $*, \Gamma$ & ا. الفاعلية الذاتية \\
\hline & & $\cdots$ & $* *,\lceil 1)$ & $* *, 0\lceil 1$ & $* *, r \leq V$ & $* *, \sum\lceil 0$ & $* *, 0 \Delta \varepsilon$ & $.0 \varepsilon$ & آ. الرابطة العاطفية \\
\hline & $\ldots$ & $* *, \vee 90$ & $* *, r \Gamma V$ & $* *, 0 \leq \varepsilon$ & $* *, r \leq \varepsilon$ & $* *, 010$ & $* *, \Sigma\rceil r$ &,$\sum \varepsilon 0$ & سـ. الأهـداف \\
\hline$\cdots$ & $* *, 79 \wedge$ & $* *, V \leqslant 1$ & $*, \Gamma \cdot r$ & $*, \Gamma \cdot \Gamma$ & $* *, \Sigma \cdot \Delta$ & $* *, \Gamma \leq V$ & **, r r &,$\cdots \varepsilon$ & ع. المهمات \\
\hline 119 & $* *, 940$ & $* *, 901$ & $* *, r \cdot r$ & $* *, 0 \leq 1$ & $* *, r \wedge \Gamma$ & $* *, \leq 90$ & $* *, 0 \Gamma 0$ & 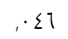 & 0. التحـالف الإشـرافي \\
\hline$* *$ & & & & & & & & & \\
\hline
\end{tabular}


كلما كان ختالف العمل الإشـرافي أقوى، كلما زاد الاتفاق

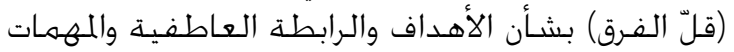

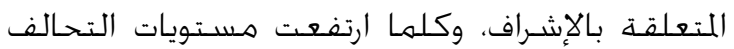
الإشـرافي بين المشـرف والمتدرب، فإن إدراكات المتدربين المانين

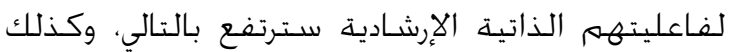

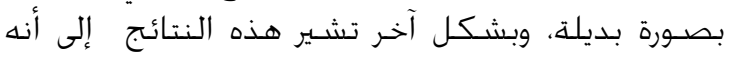

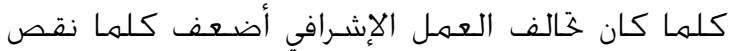

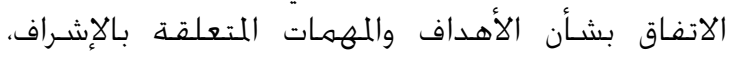

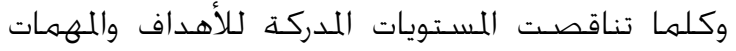

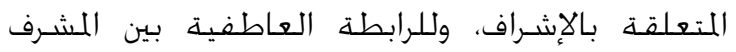

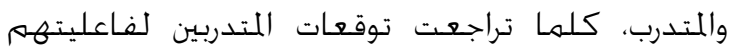
الذاتية الإرشادية.

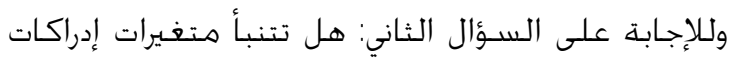

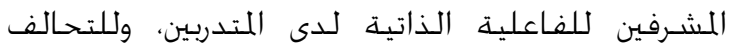

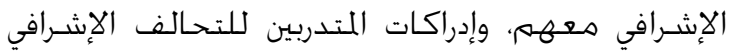

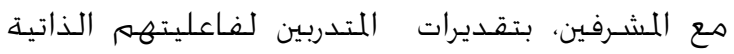

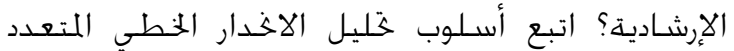
بانئ (Multiple Linear Regression)

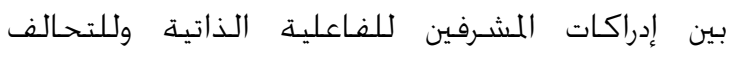

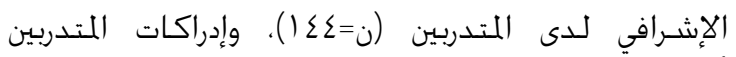

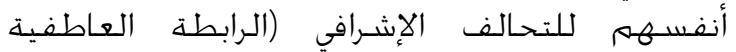

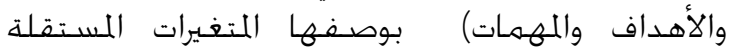
المتنبئة (Predictors)، وإدراكات هؤلاء المتدربين للفاعلية

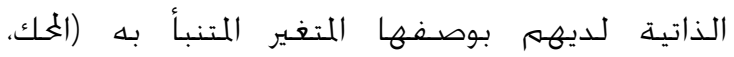
Criterion

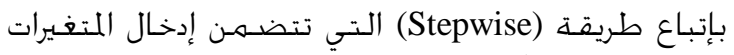

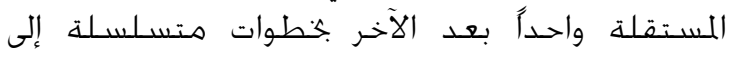

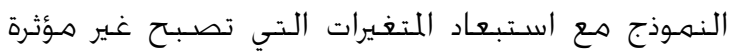
بوجود بقية المتغيرات (جدول 0).

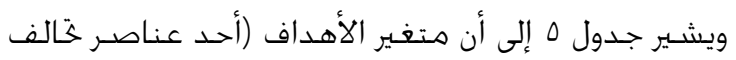

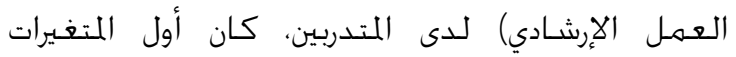

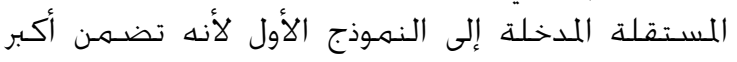

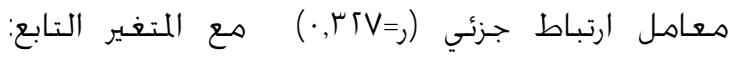

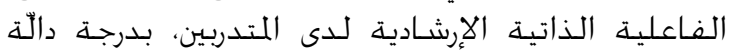

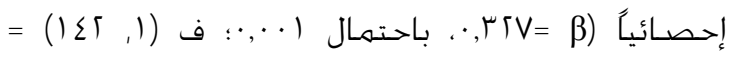

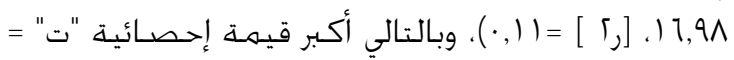

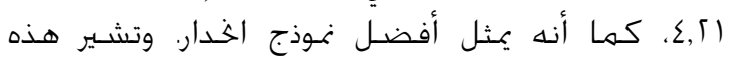

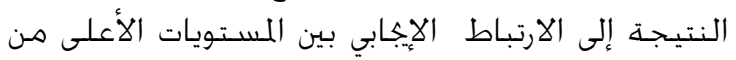

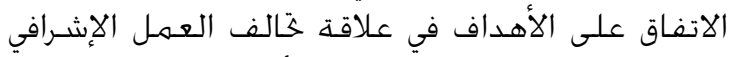

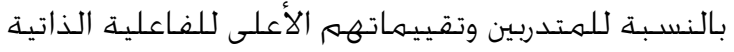

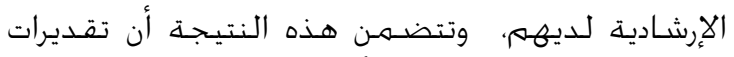

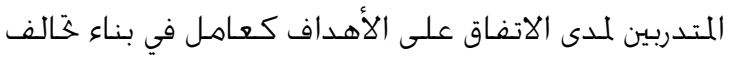

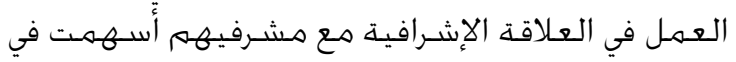

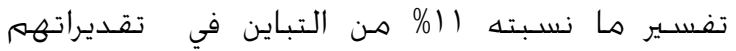

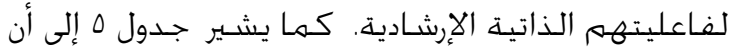

الإشـرافي ومقاييســ الفرعية الرابطة العاطفية

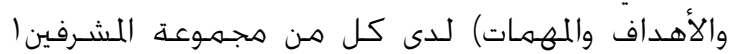

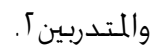

ويتضح من جدول ع وجود ارتباطات موجبة دالّة إحصائياً

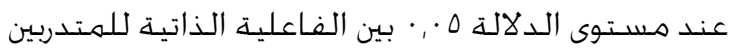

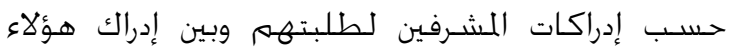

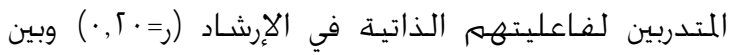

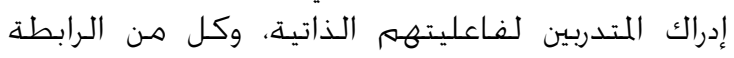

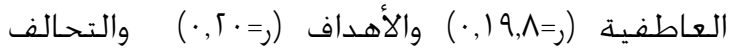

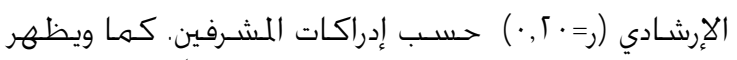

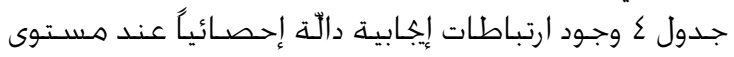

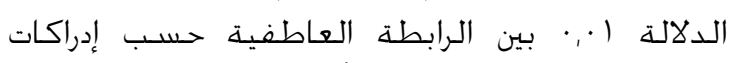

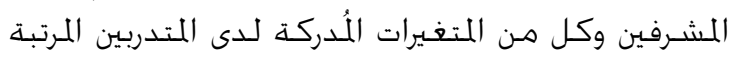

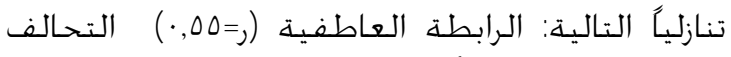

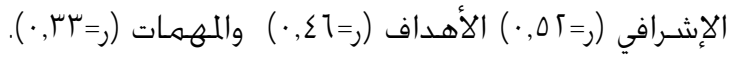

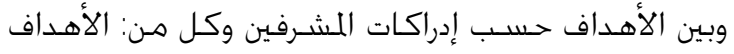

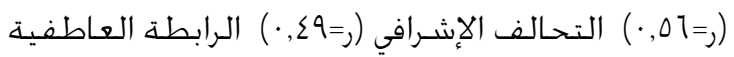

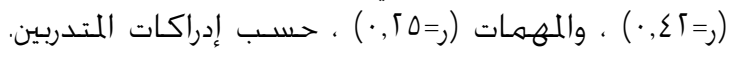

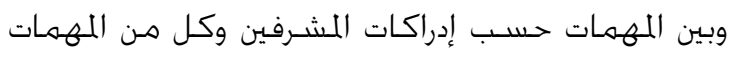

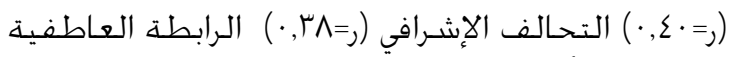

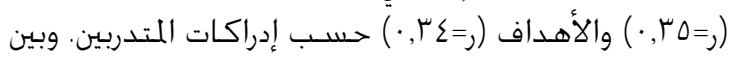

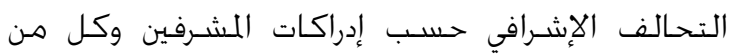

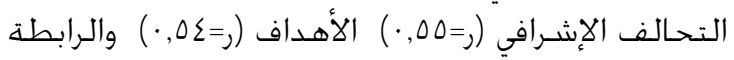

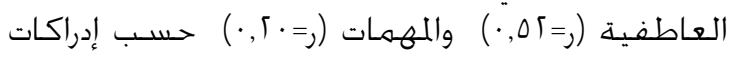

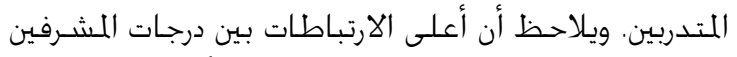

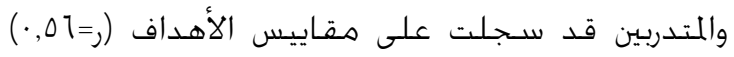

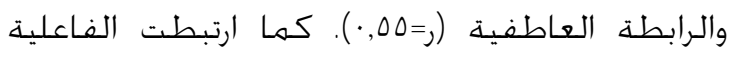

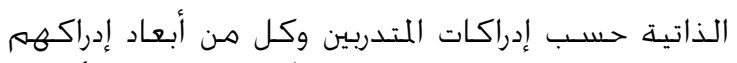

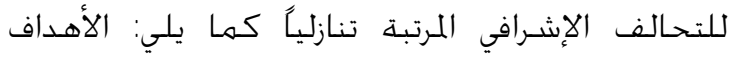

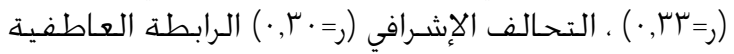

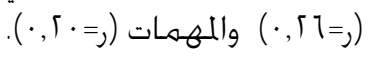

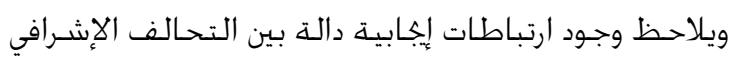

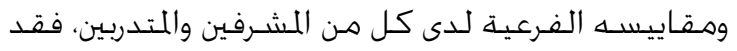

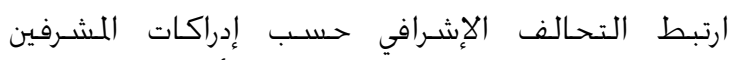

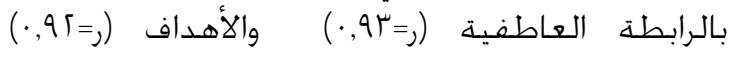

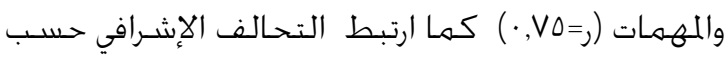

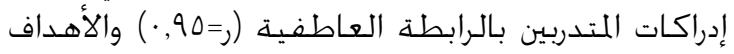

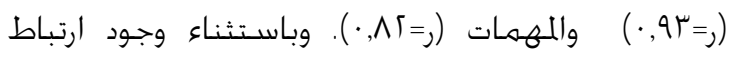

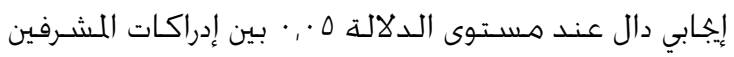
للفاعلية الذاتية لدى طلبتهم المتدربين وبين إدراكهم إدراته

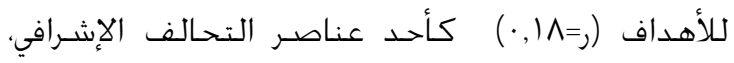

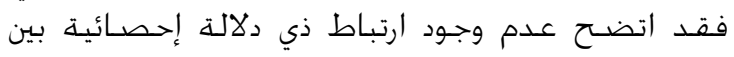

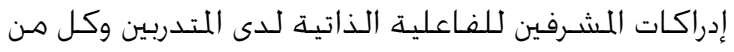

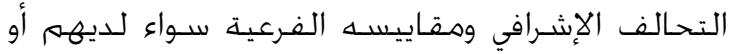

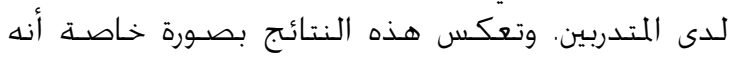




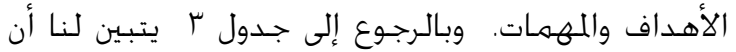

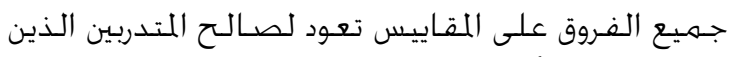
سجلوا درجات أعلى من درجات المشـرفين.

جدول 1

قيمة اختبار"ت" لدلالة الفروق بين منوسطات المشرفين والمتدربين على مقايبس الفاعلية الذاتبة والتحالف الإشرافي

\begin{tabular}{|c|c|c|c|}
\hline مسـتوى الدلالة & قيمة & الحرية & المقياس \\
\hline$* \cdot, \cdot\lceil\Lambda$ & $\Gamma, \Gamma \Gamma$ & $1 \leqslant r$ & الذاعاتية \\
\hline$* \cdot, \cdot 1 \Gamma$ & $\Gamma, \Delta r$ & $1 \varepsilon r$ & الإشــالف \\
\hline$\Delta \Gamma \varepsilon_{1}$ & $\cdot, \pi \wedge$ & $1 \leqslant r$ & العاطفية الرابطة \\
\hline$* * \cdot, \ldots$ & $r, 1$. & $1 \leqslant r$ & الأهداف \\
\hline$* * ., \ldots$ & $r, \mathrm{vq}$ & $1 \leqslant r$ & المهمات \\
\hline
\end{tabular}

\section{مناقشــة النتائج والتوصـيات}

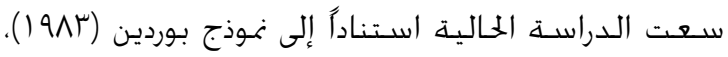

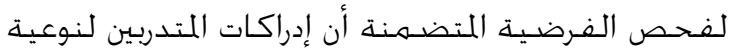

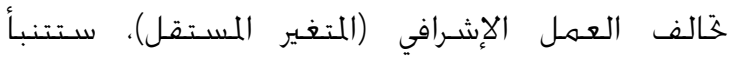

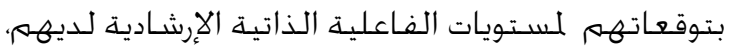

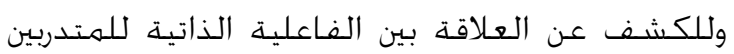

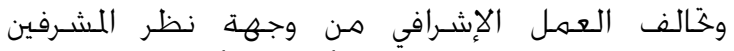

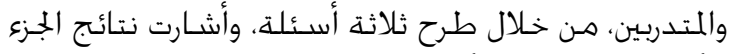

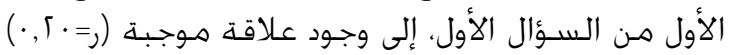

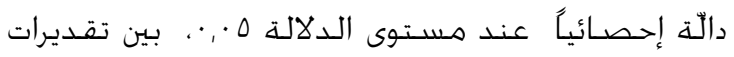

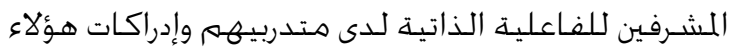

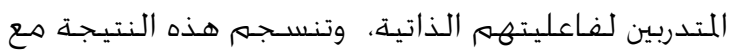

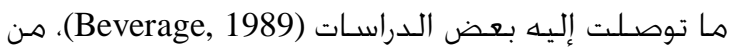

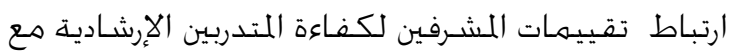

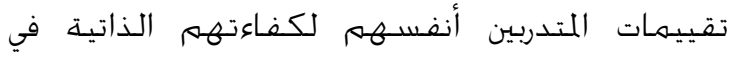
الإرشاد. وتدعم النتائج الحالية توصيات بعض الفر الباحثين

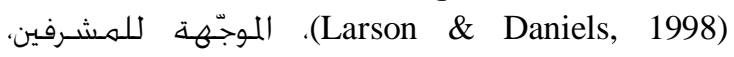

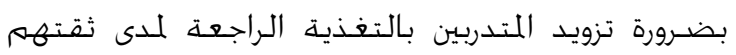
(Steward, Breland \& Neil, بكفاءتهم الإرشادية

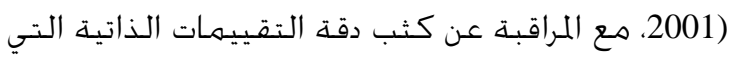
يضعها هؤلاء المتدربين بشأن كفاءتهم الإرشادية.

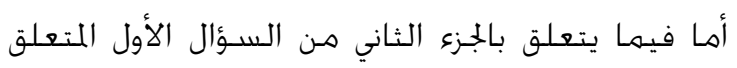

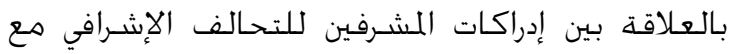

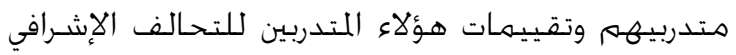

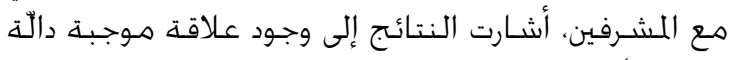

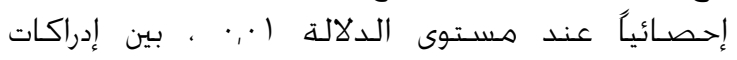

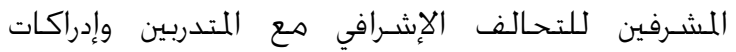

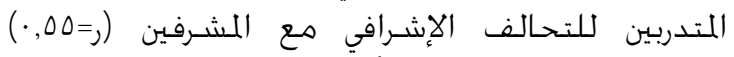

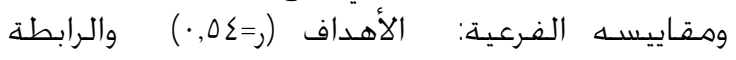

إدراكات المشـرفين للفاعلية الذاتية لدى متدربيهم كان النان النهان

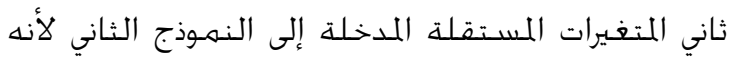

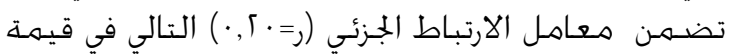

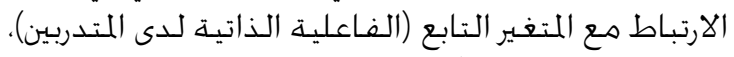

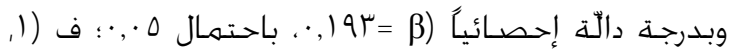
(إ)

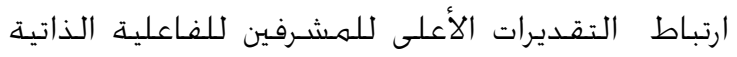

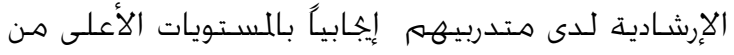

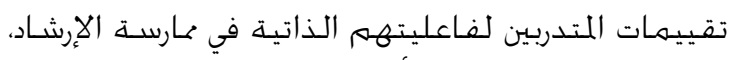

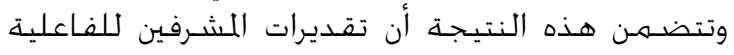

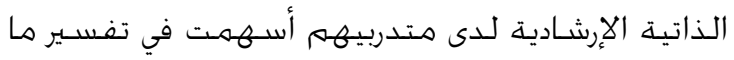

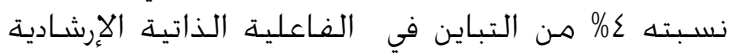

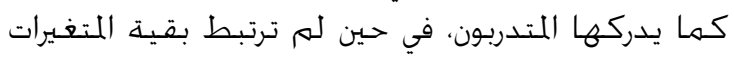

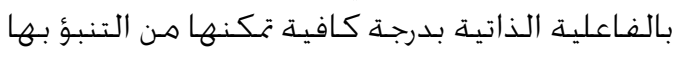

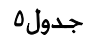

خليل الاخدار المتعدد للمتغير التابع (الحك) الفاعلية الذاتية لدى المتدربين،

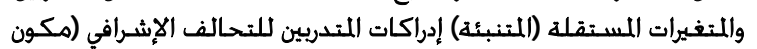

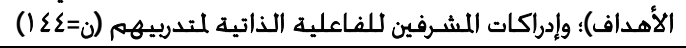

\begin{tabular}{|c|c|c|c|}
\hline إحصـائي" ت" & 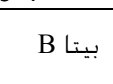 & المتغيرات المتنبئة & المتغذير التابع \\
\hline \multirow[t]{2}{*}{$* * \sum, 1\lceil 1$} & $\mu T V$ & الادراكات المتـدربين) (حسبب) & 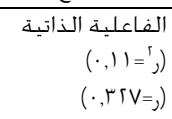 \\
\hline & & \multicolumn{2}{|c|}{ 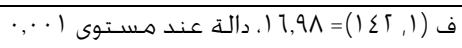 } \\
\hline $\begin{array}{l}* * \varepsilon, 1 . \\
* \tau, \Sigma V\end{array}$ & $\begin{array}{l}.45 . \\
.194\end{array}$ & 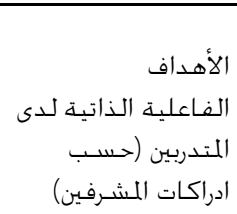 & 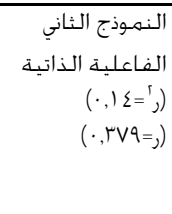 \\
\hline & & \multicolumn{2}{|c|}{ 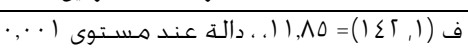 } \\
\hline
\end{tabular}

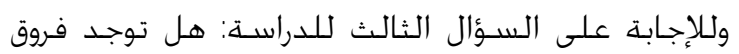

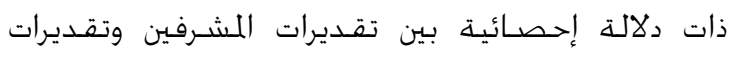

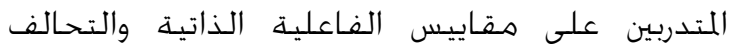

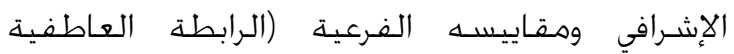

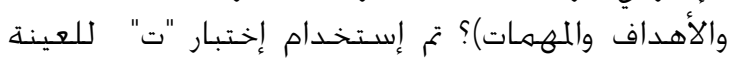

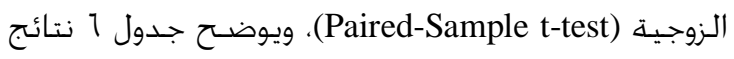
اختبار "ت" للفروق بين متوسطات درجات المشـرفين

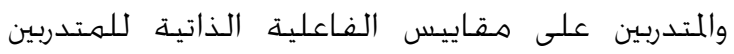

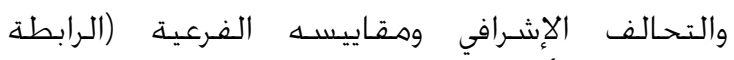
العاطفية والأهداف واللمهمات).

ويبين جدول 1 وجود فروق دالّة بين مجموعتي المشرفين

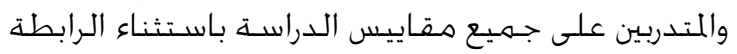

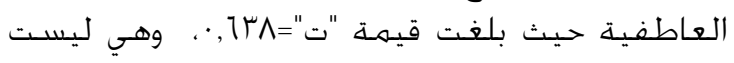

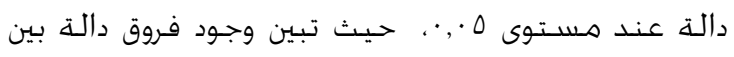

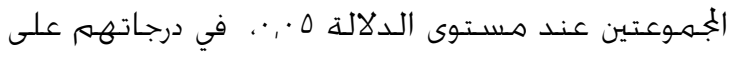

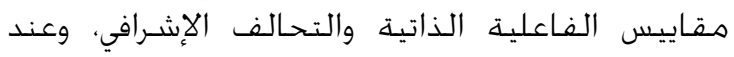

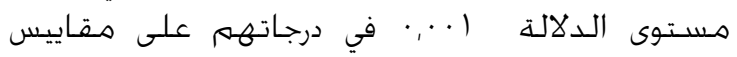




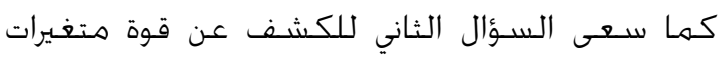
إدراكات المشـرفين للفاعلية الذاتية لدى لـانية المتدربين،

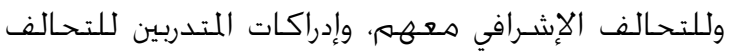

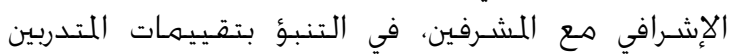

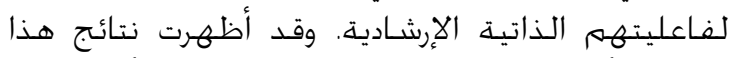

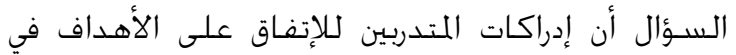

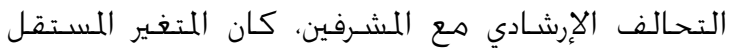

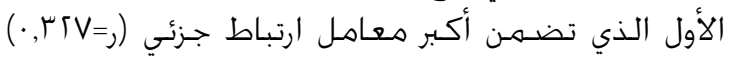

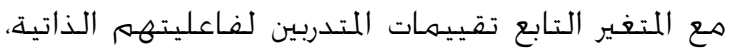

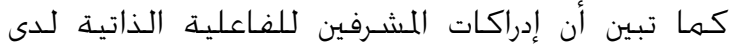

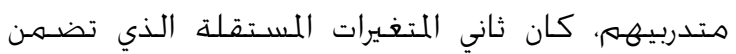

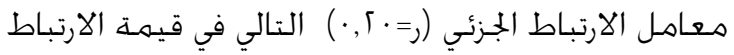

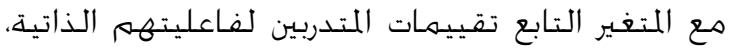

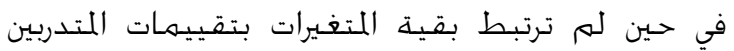
لفاعليتهم الذاتية بدرجة كافية تمكنها من التنبؤ بهنها.

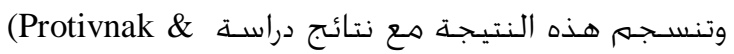
Davis, 2008)

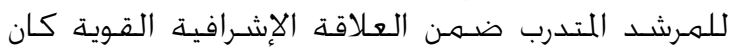

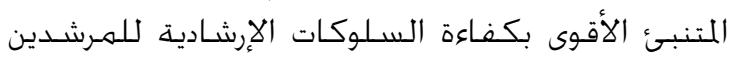

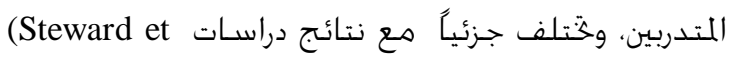

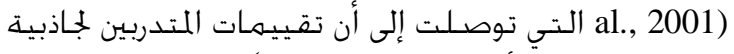

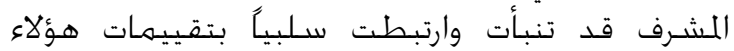
المتدربين لكفاءتهم الذاتية الإرشادية.

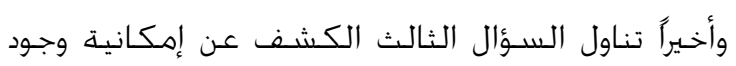

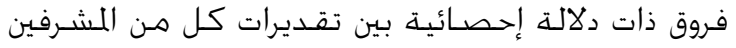

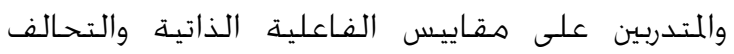

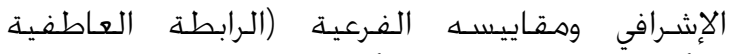

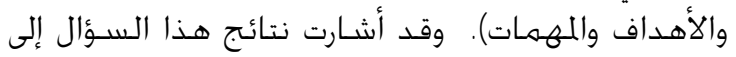

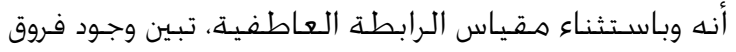

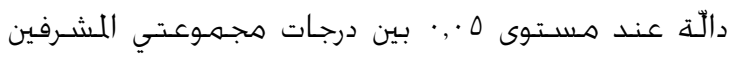

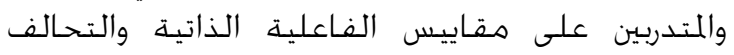

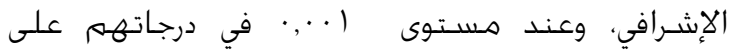

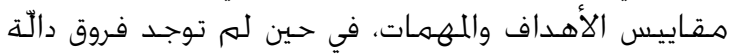

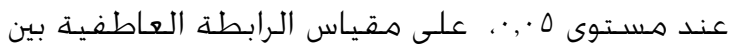

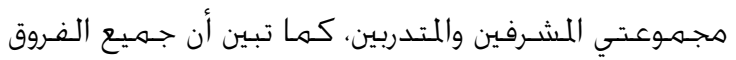

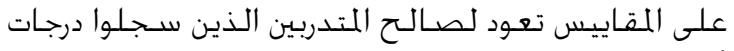

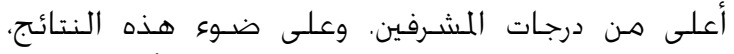

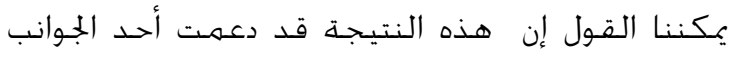

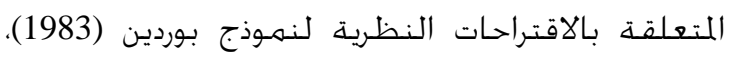

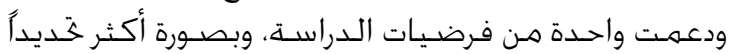

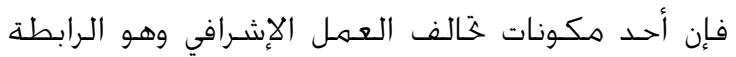

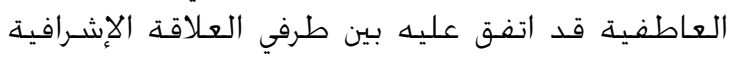

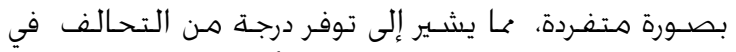

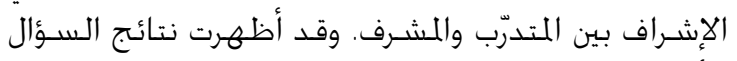

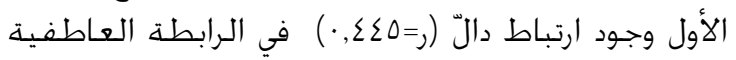

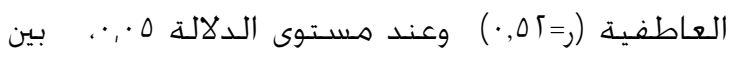

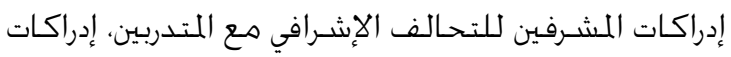

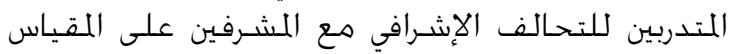

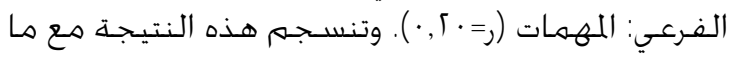

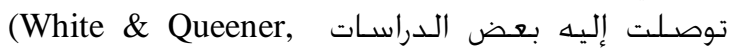

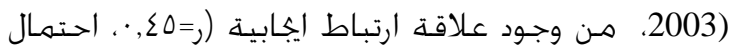

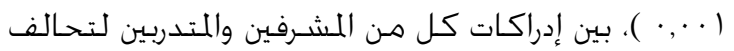

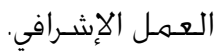

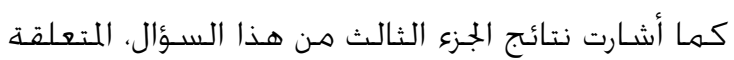

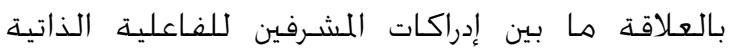

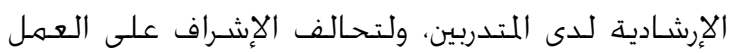

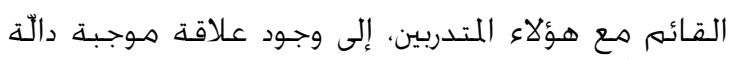

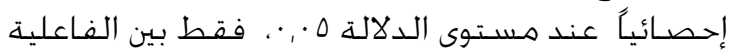

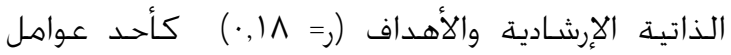

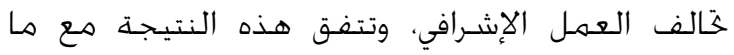
توصلت إليه بعض الدراسـات (Efstation et al., 1990).

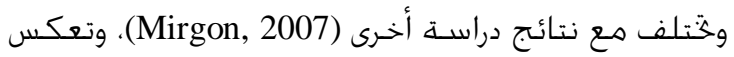

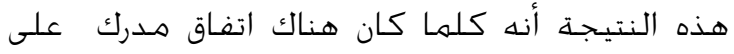

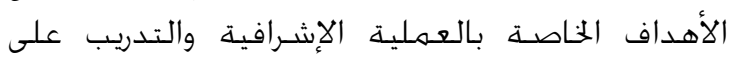

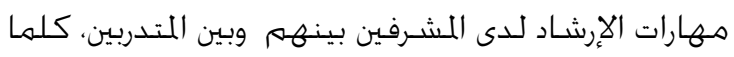
ارتفعت إدراكات المشـرفين للفاعلية الذاتية للمتدربين.

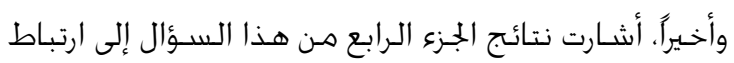

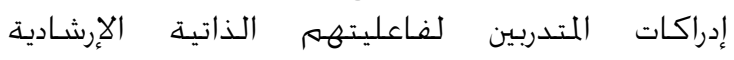

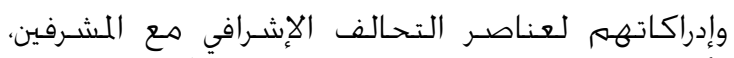

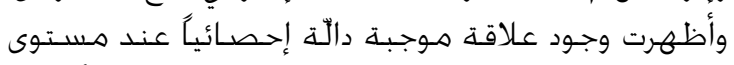

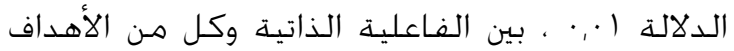

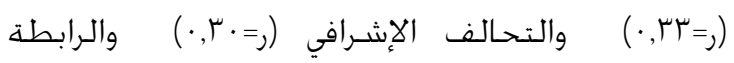

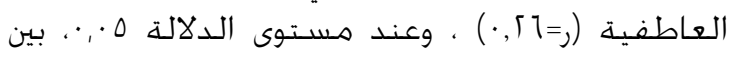

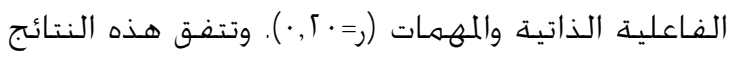

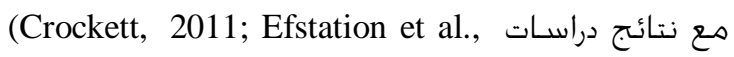
1990; Humeidan, 2002; Lorenz, 2009; Morcos, (2010، التي توصلت إلى وجود علاقة موجبة دالة

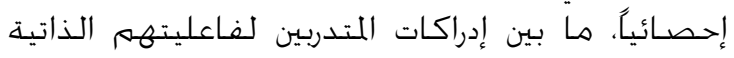

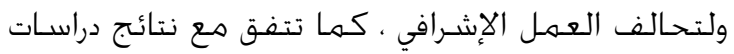
(Friedlander \& Snyder, 1983; Patton \& Kivlighan, (1997، التي توصلت إلى وجود علاقة دالة مالة مالين بين

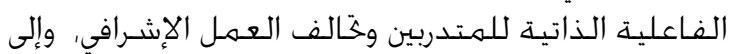

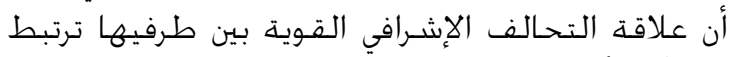

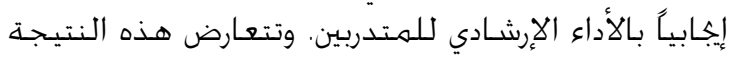

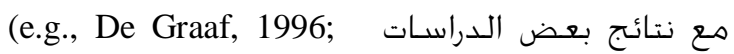
(Ladany et al., 1999)

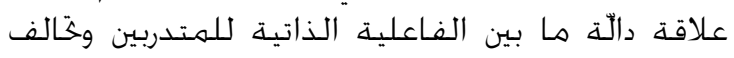

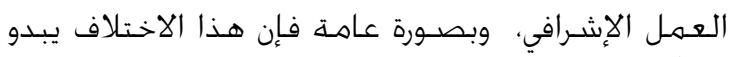
مثيراً للاهتهام ويختاج إلى فحص ودراسـة مستقبلية. 
إن نتائج الدراسـة الحالية ختتوي على تضـمينات

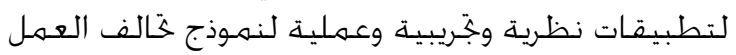

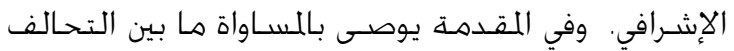

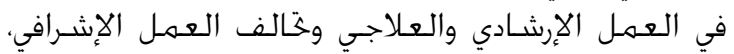

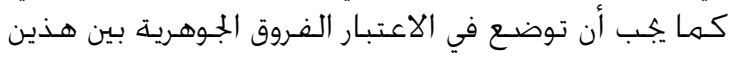

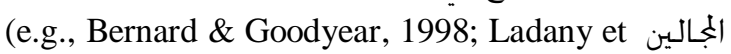
وبصورة محددة فإن المتدربين يقيمون

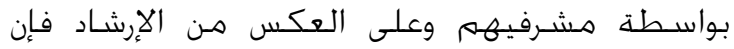

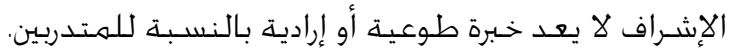

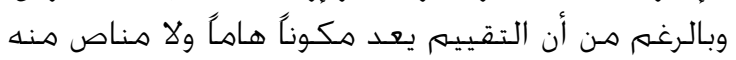

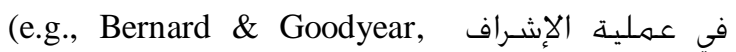

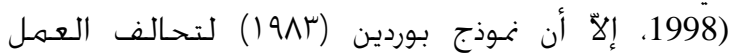

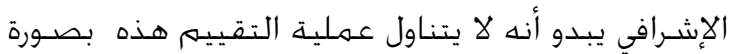

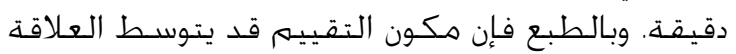

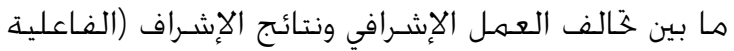

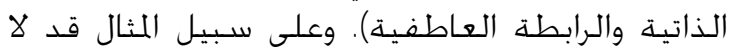

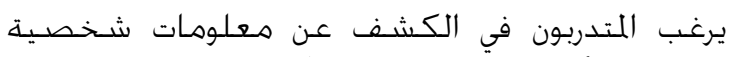

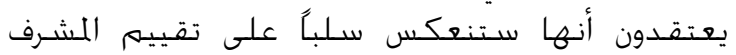
لأدائهم Ladany, Hill, Corbett, \& Nutt, 1996; Olk ( F Friedlander, 1992)

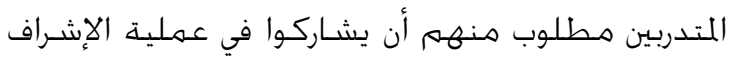

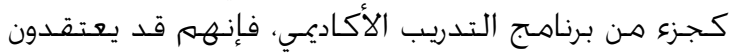

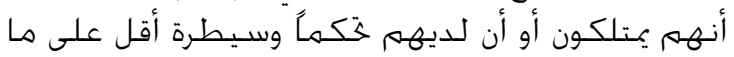

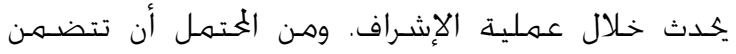

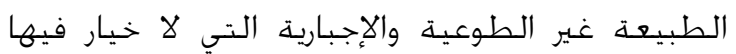

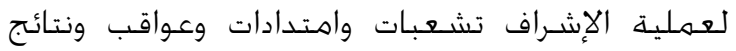
ليس فقط بالنسبة للرابطة العاطفية لكن أيضًاً

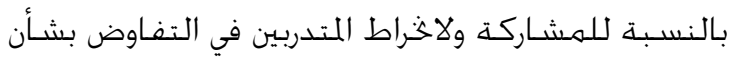

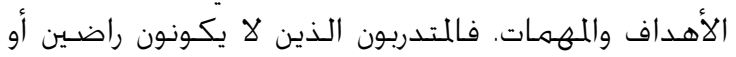

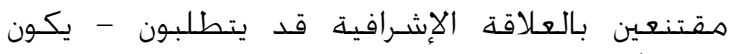

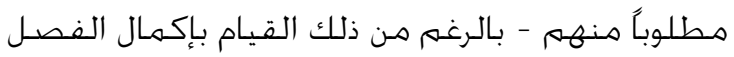

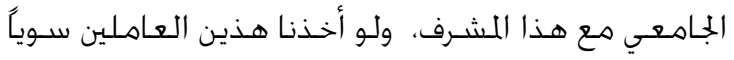

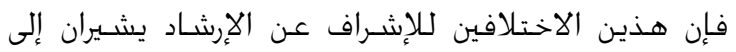

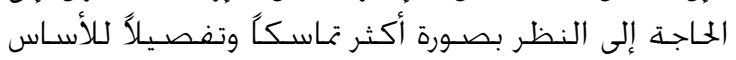

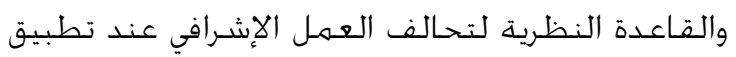
هذه القاعدة النظرية على الإشـراف الإرشادي والعلاجي.

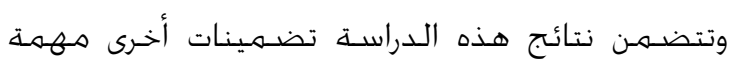

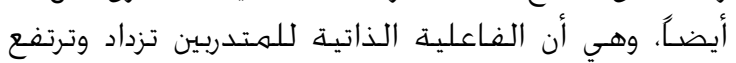

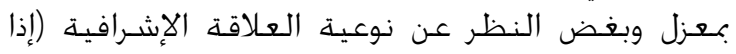

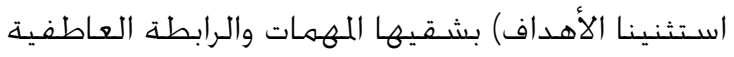

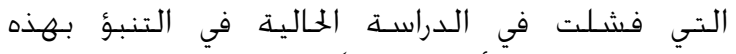

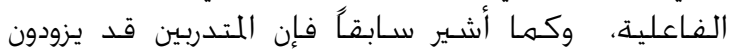

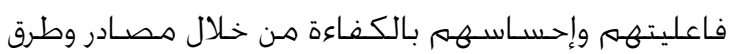

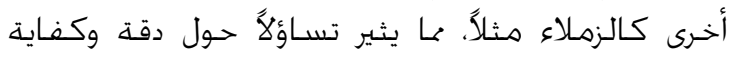

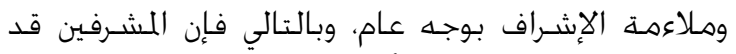

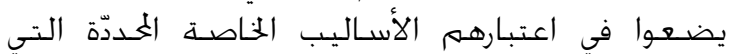

لدى كل من المشـرفين والمتدربين، وقد يفسّر ذلك بأنه

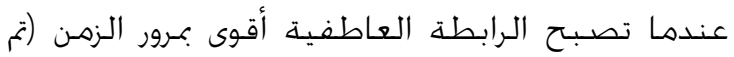

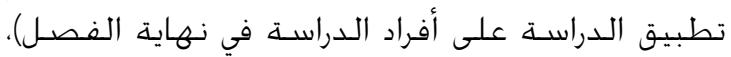

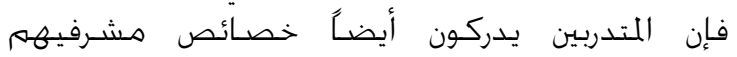

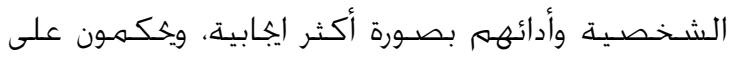

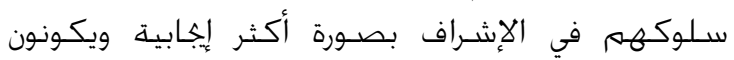

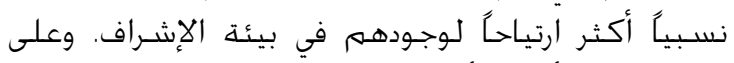

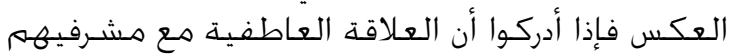

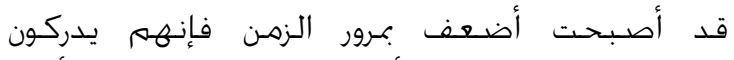

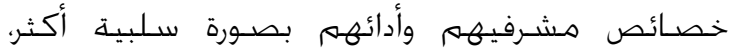

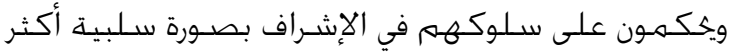

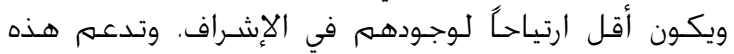

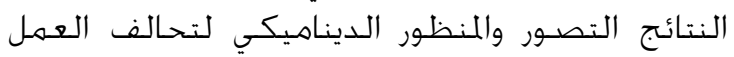

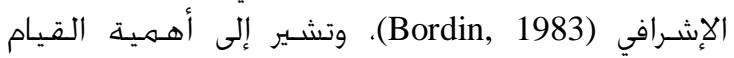

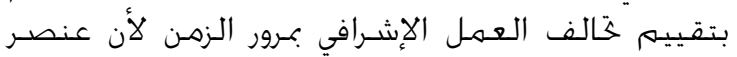

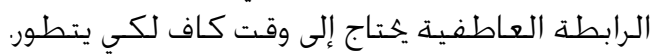

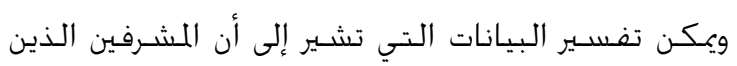

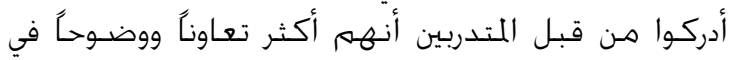

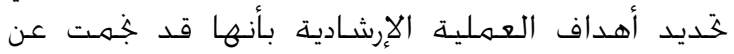

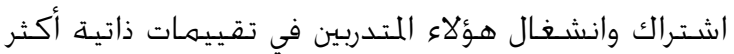

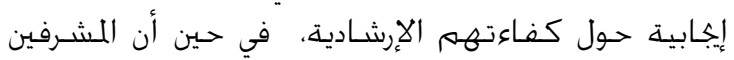

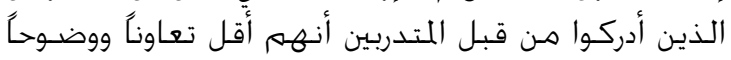

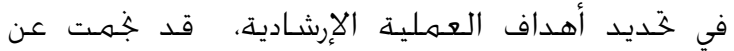

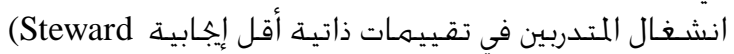
et al., 2001)

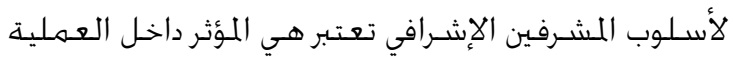

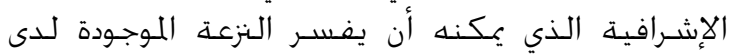

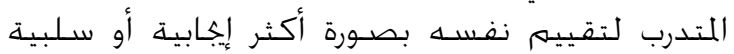

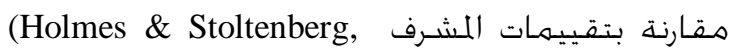
(1990، فمدى الدرجة التي يدرك فيها المتدرب المشـرفين

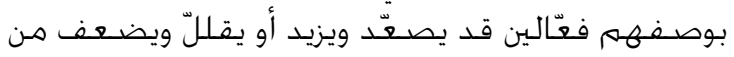

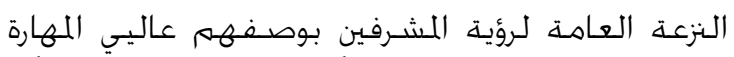

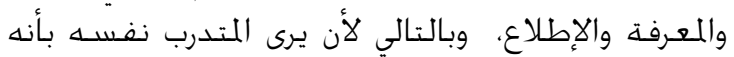
أكثر أو أقل مهارة وكفاءة في تأدية المهارات الإرشادية لإنالية (Stoltenberg, McNeill, \& Delworth, 1998) ، ويقيّم الارنم

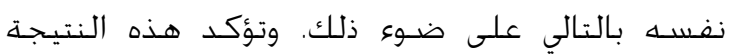

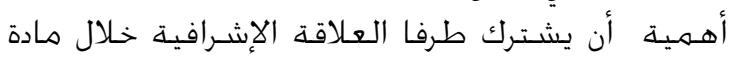

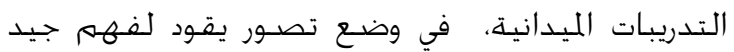

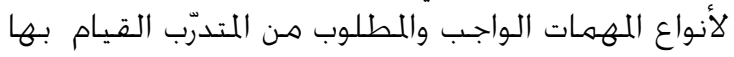

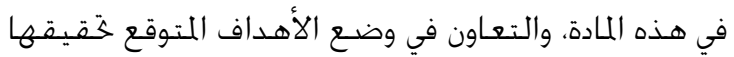

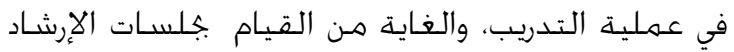

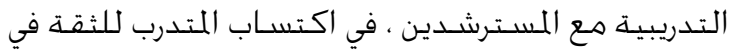

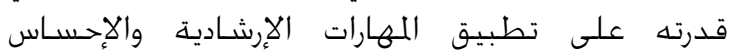
بك بـاءتـه. 
وتوسيع نتائزج هذه الدراسـة. وقد توجـه الاقتراحات التالية

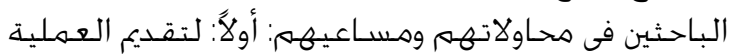

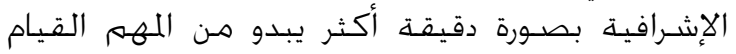

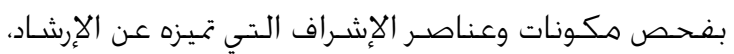

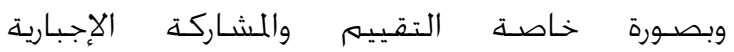
(Evaluation and involuntary participation) وجدت الدراسـة الحالية تفاعلات وتبادلات تفاعلية عالية

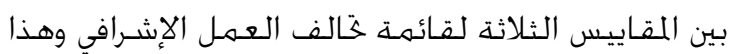

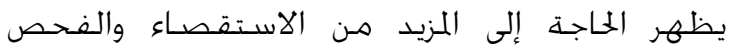

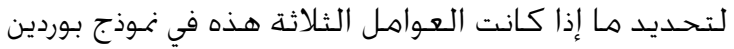

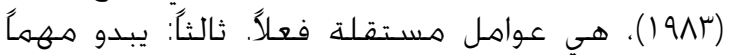

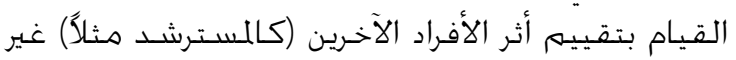

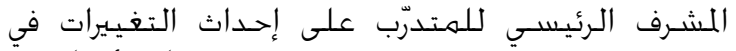

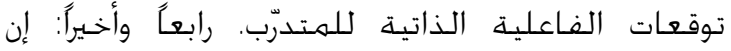

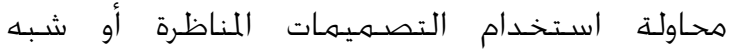
(Analogue or Quasi-experimental التجريبية designs)

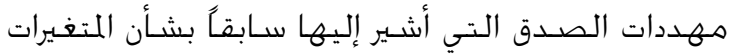

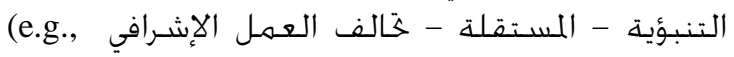
Sumerel \& Borders, 1996)

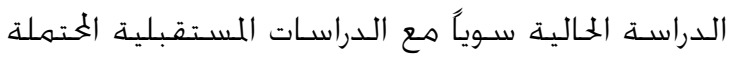

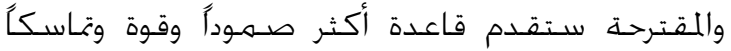

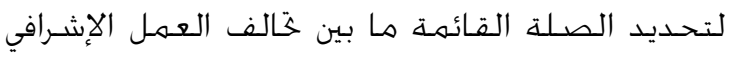
ومخرجات العملية الإشـرافية برمتها.

\section{المراجع \\ References}

Bahrick, A. (1989). Role induction for counselor trainees: Effects on the supervisory working alliance. Unpublished doctoral dissertation, The Ohio State University, Columbus, Ohio.

Bahrick, A., Russell, R., \& Salmi, S. (1991). The effects of role induction on trainees' perceptions of supervision. Journal of Counseling and D evelopment, 69, 434 - 438.

Bandura, A. (1977). Self-efficacy: Toward a unifying theory of behavior change. Psychological Review, 84, 191-215.

Bandura, A. (1991). Social cognitive theory of selfregulation. Organizational Behavior and Human D ecision Processes, 50, 248-287.

Bandura, A. (1993). Perceived self-efficacy in cognitive development and functioning. Educational Psychologist, 28, 117-148.

Bandura, A. (2006). Guide for constructing SE scales. In F. Pajares \& T. Urdan (eds.). SE Beliefs of adolescents. Greenwich, CT: Information Age Publishing.

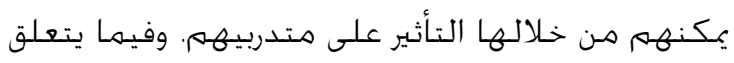
بممارسات الإشـراف وخالف العمل الإشـرافي فإن نـان نتائج

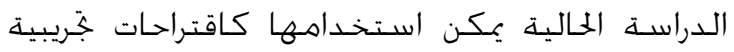

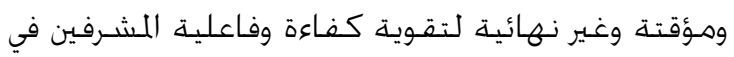
عملهم مع المتدربين. ويجب ملاحظة إن تفسير نتائج الدراسـة الحالية يبدو

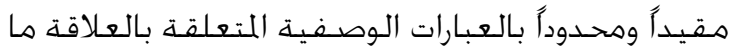

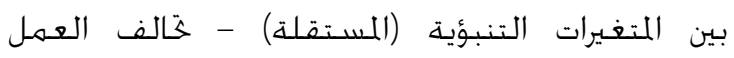
الإشـرافي، والمتغيرات الماتكية ل (التابعة) - الفاعلية

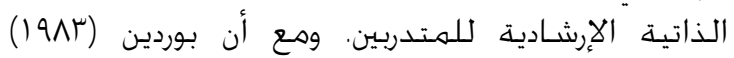

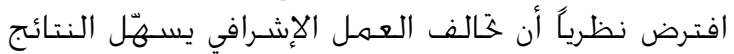

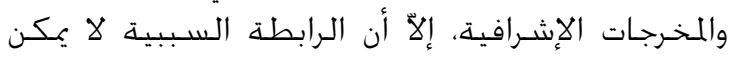

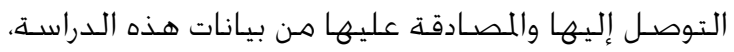

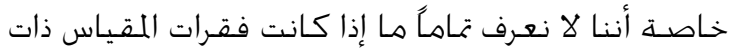

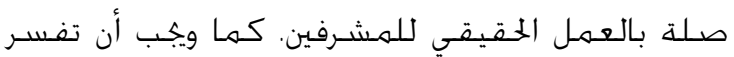

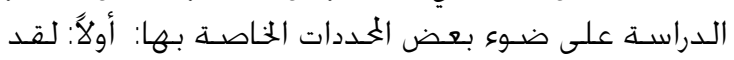

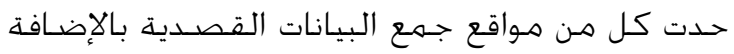

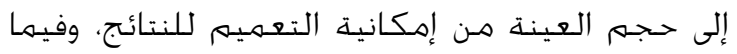

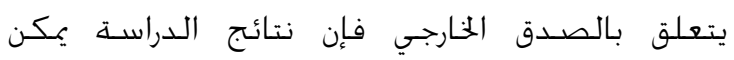

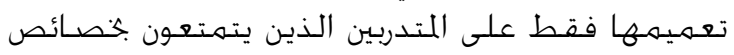

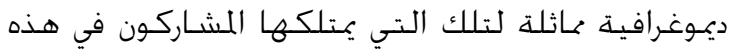

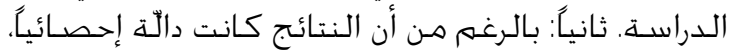

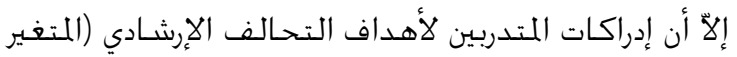

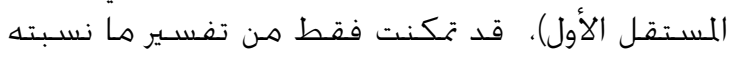

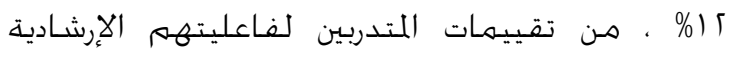

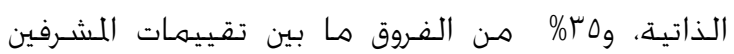

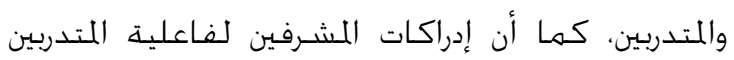

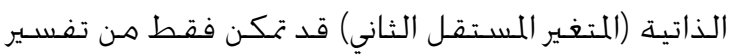

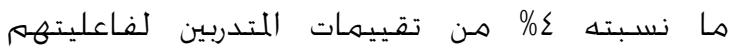

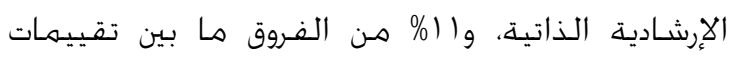

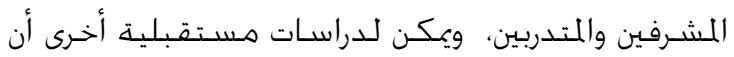

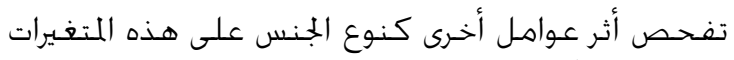

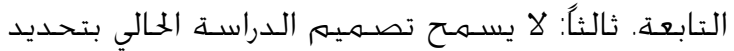

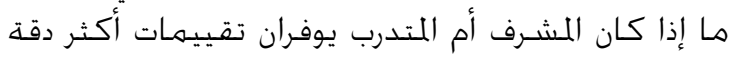

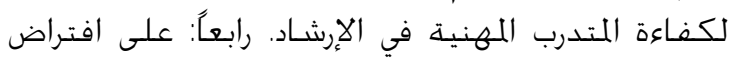

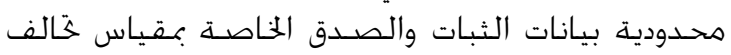

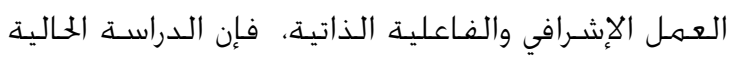

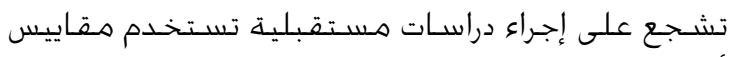

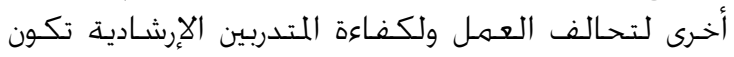
عالية الثبات والصـدق.

وفي النهاية وبصـورة أسـاسية فإن إجراء دراسـة

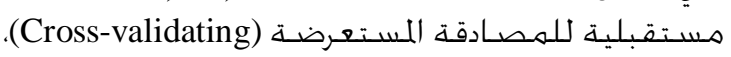

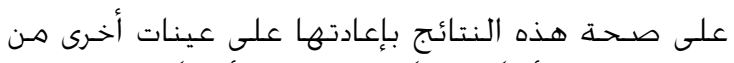

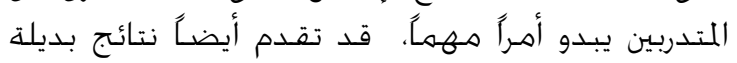

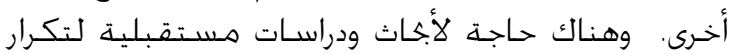


Bernard, J. (1997). The discrimination model. In C. E. Watkins, Jr. (Ed.), Handbook of psychotherapy supervision (pp. 447-507). New York: Wiley.

Bernard, J., \& Goodyear, R. (1998). Fundamentals of clinical supervision (2nd. ed.). Needham Heights, MA: Allyn \& Bacon.

Beutler, L., Machado, P., \& Neufeldt, S. (1994). Therapist variables. In A. E. Bergin \& S. L.Garfield (Eds.), $\mathrm{H}$ andbook of Psychotherapy and Behavior Change (pp. 229-269). New York: Wiley \& Sons.

Borders, L. (2001). Counseling supervision: A deliberate educational process. In D. C. Locke, J. E. Myers, \& E. L. Herr (Eds.), The handbook of counseling, (pp. 417 - 432). Thousand Oaks, California, CA: Sage Publications.

Bordin, E. (1979). The generalizability of the psychoanalytic concept of the working alliance Psychotherapy: Theory, Research, and Practice, 16, 252-260.

Bordin, E. (1983). A working alliance model of supervision. The Counseling Psychologist, 11(1), $35-42$.

Bordin, E. (1994). Theory and research on the therapeutic working alliance: N ew directions. In A. O. Horvath \& L. S. Greenberg (Eds.), The working alliance: Theory, research, and practice (pp. 13-37). New York: John Wiley.

Cohen, J., \& Cohen, P. (1983). Applied multiple regression/correlation analysis in behavioral sciences. Hillsdale, NJ: Erlbaum

Cook, T., \& Campbell, D. (1979). QuasiExperimentation: Design and Analysis for Field Settings. Rand McN ally, Chicago, Illinois.

Crockett, S. (2011). The role of supervisor-supervisee cultural differences, supervisor multicultural competence, and the supervisory working alliance in supervision outcomes: A moderated mediation model. Ph.D. dissertation, Old Dominion University, United States, Virginia. Retrieved November 10, 2011, from Dissertations \& Theses: Full Text.(Publication No. AAT 3455280).

Daniels, J., \& Larson, L. (2001). The impact of performance feedback on counseling selfefficacy and counselor anxiety. Counselor Education \& Supervision, 41 (2), 120-130.

De Graaf, R. (1996). Counselor self-efficacy development: An examination over time of the influence of trainee exposure to clients, negative affectivity and the supervisory alliance. Ph.D. dissertation, Loyola University of Chicago, United States, Illinois. Retrieved December 9, 2008, from Dissertations \& Theses: Publication No. AAT 9623415).
Efstation, J.,Patton, M., \& Kardash, C. (1990). Measuring the working alliance in counselor supervision. Journal of Counseling Psychology, 37, 322-329.

Friedlander, M., \& Snyder, J. (1983). Trainees' expectations for the supervisory process: Testing a developmental model. Counselor Education and Supervision, 22, 342-348.

Gelso, C., \& Carter, J. (1985). The relationship in counseling and psychotherapy: Components, consequences, and theoretical antecedents. The Counseling P sychologist, 13, 155-243.

Helms, J., \& Cook, D. (Eds.).(1999).U sing race and culture in counseling and psychotherapy. Boston: Allyn \& Bacon.

Holmes, D., \& Stoltenberg, C. (1990). Supervision: A comparison of traines' and supervisors' perceptions of development. ERIC Document Reproduction Service No. ED 318959.

Holloway, E., \& Neufeldt, S. (1995). Supervision: Its contributions to treatment efficacy. Journal of Consulting and Clinical Psychology, 63, 207-213.

Horvath, A., \& Greenberg, L. (1986). The development of the Working Alliance Inventory. In L. Greenberg \& W. Pinsof (Eds.), The psychotherapeutic process: A research handbook (pp. 529 -556). New York: Guilford Press.

Horvath, A., \& Greenberg, L. (1989). The development and validation of the Working Alliance Inventory. Journal of Counseling Psychology, 36, 223-233.

Humeidan, M. (2002). Counseling self-efficacy, supervisory working alliance, and social influence in supervision. Ph.D. dissertation, Ball State University, United States, Indiana. Retrieved November 10, 2011, from Dissertations \& Theses: Full Text.(Publication No. AAT 3046083).

Ladany, N. (2004). Psychotherapy supervision: What lies beneath. Psychotherapy Research, 14, 1-19.

Ladany, N., \& Friedlander, M. (1995). The relationship between the supervisory working alliance and trainees' experience of roleconflict and role ambiguity. Counsel or Education \& Supervision, 34, 220-231.

Ladany, N., \& Malouf, M . (2010). Understanding and conducting supervision research. In $\mathrm{N}$. Ladany \& L. Bradley (Eds), Counselor supervision, principles, process, and practice $\left(4^{\text {th }}\right.$, ed., pp. 353-388). New York, NY: Routledge.

Ladany, N., Brittan-Powell, C., \& Pannu, R. (1997). The influence of supervisory racial identity interaction and racial matching on the 
supervisory working alliance and supervisee multicultural competence. Counsel or Education and Supervision, 36, 284-304.

Ladany, N., Ellis, M., \& Friedlander, M. (1999). The supervisory working alliance, trainee selfefficacy, and satisfaction. Journal of Counseling \& D evelopment, 77 (4), 447- 455.

Ladany, N., Hill, C., Corbett, M., \& N utt, E. (1996). Nature, extent, and importance of what psychotherapy trainees do not disclose to their supervisors. Journal of Counseling Psychology, 43, 10-24.

Ladany, N., Lehrman-Waterman, D., Molinaro, M., \& Wolgast, B. (1999). Psychotherapy supervisor ethical practices: Adherence to guidelines, the supervisory working alliance and supervisee satisfaction. The Counseling Psychologist, 27, 443-475.

Larson, L. (1998). The social cognitive model of counselor training (Monograph). M ajor contribution for The Counseling Psychologist, 26, 219-273.

Larson, L., \& Daniels, J. (1998). Review of the counseling self-efficacy literature (Monograph). Major contribution for The Counseling Psychologist, 26, 179-218.

Larson, L., Cardwell, T., \& Majors, M. (1996, August). Counseling self-efficacy, job satisfaction, and work environment: Predictors of burnout. Paper presented at the meeting of the American Psychological Association, Toronto, Canada.

Lauver, P., \& Harvey, D. (1997). The practical counselor: Elements of effective helping. Pacific Grove, CA: Brooks/ Cole.

Myers, R. H. (1990). Classical and M odern Regression with Applications. PWS-Kent Publishing Company.

Mirgon, T. (2007). The relationship of supervisory working alliance and counselor self-efficacy to supervise development: An exploratory study. Ph.D. dissertation, Northern Arizona University, United States, Arizona. Retrieved November 10, 2011, from Dissertations \& Theses: Full Text.(Publication No. AAT 3257737).

Morcos, S. (2010). Supervision factors related to the self-efficacy of novice mental health workers. Psy.D. dissertation, Mary wood University, United States, Pennsylvania. Retrieved November 10, 2011, from Dissertations \& Theses: Full Text.(Publication No. AAT 3407218).

Muse-Burke, J., Ladany, N., \& Deck, M. (2001). The supervisory relationship. In L. Bradley \& N.
Ladany (Eds.), Counselor Supervision (3rd. ed.). (pp.28-62). Philadelphia, PA: Taylor Francis.

Olk, M. E., \& Friedlander, M. L. (1992). Trainees' experiences of role conflict and role ambiguity in supervisory relationships. Journal of Counseling P sychology, 43, 3-9.

Patton, M., \& Kivlighan, D. (1997). Relevance of the supervisory alliance to the counseling alliance and to treatment adherence in counselor training. Journal of Counseling P sychology, 44 (1), 108-115).

Protivnak, J., \& Davis, T. (2008, May 7). The impact of the supervision relationship on the behaviors of school counseling interns. Journal of School Counseling, 6 (19). Retrieved December, 9, 2008, from http:/ / www.jsc.montana.edu/ articles/ v6n19. pdf

Robinson, J. (2001). Relationships betwen perceived supervisory styles and counseling students' selfefficacy in practicum. Ph.D. dissertation, University of South Carolina, United States, South Carolina. Retrieved November 10, 2011, from Dissertations \& Theses: Full Text.(Publication No. AAT 3020973).

Schuman, H., \& Kalton, G. (1985). Survey methods. In G. Lindzey \& E. A ronson (Eds.), $\mathrm{H}$ andbook of Social Psychology, Volume 1 (pp.635-697). New York: Random House.

Steward, R., Breland, A., \& N eil, D. (2001). N ovice supervisees' self-evaluations and their perceptions of supervisor style. Counselor Education and Supervision, 41 (2), 131-141. Retrieved April, 21, 2005 from http:/ / www.highbeam.com/ library/ doc3.asp ?ctrlInfo=Round91\%3A Prod\%3ADOC\%3

Stoltenberg, C. (1981). A pproaching supervision from a developmental perspective: The counselor-complexity model. Journal of Counseling P sychology, 28, 59- 65.

Stoltenberg, C., \& Delworth, U. (1987). Supervising counselors and therapists: A developmental approach. San Francisco, CA: Jossey-Bass.

Stoltenberg, C., McN eill, B., \& Delworth, U. (1998). IDM Supervision: An integrated developmental model for supervising counselors and therapists. San Francisco: Jossey-Bass.

Sumerel, M., \& Borders, L. (1996). Addressing personal issues in supervision: Impact of counselors' experience level on various aspects of the supervisory relationship. Counselor Education and Supervision, 35(4), 268-286

Tuckman, B. W. (1999). Conducting educational research (5 $\left.5^{\text {th }} . e d.\right)$. Harcourt Brace $\&$ Company. 
Watkins, C. (Ed.).(1997). Handbook of psychotherapy supervision. New York: Wiley.

White, V., \& Queener, J. (2003). Supervisor and supervisee attachments and social provisions related to the supervisory working alliance. Counselor Education and Supervision, 3, 13p. Retrieved April, 21, 2005 from http:/ / www.highbeam.com/ library/ doc3.asp ?ctrlInfo=Round91\%3A Prod\%3A DOC\%3

Wood, C. (2005). Supervisory Working Alliance: A Model Providing Direction for College Counseling Supervision. Journal of College Counseling, 8, 127-137. 